\title{
Metallurgical Investigations into Corrosion Damage in Homes Constructed with Problem Drywall
}

\author{
R. E. Ricker \\ D. J. Pitchure \\ M. E. Williams \\ S. A. Claggett
}

Report prepared for the U.S. Consumer Product Safety Commission Directorate for Engineering Sciences Bethesda, MD 20814

This report was prepared for the US Consumer Product Safety Commission pursuant to Interagency Agreement CPSC-I-11-0009. It has not been reviewed or approved by the Commission and may not necessarily reflect the views of the Commission.

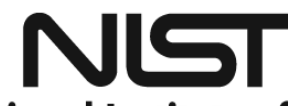

National Institute of Standards and Technology 
NISTIR 7809

\title{
Metallurgical Investigations into Corrosion Damage in Homes Constructed with Problem Drywall
}

\author{
R. E. Ricker \\ D. J. Pitchure \\ M. E. Williams \\ S. A. Claggett
}

Metallurgy Division

Materials Science and Engineering Laboratory

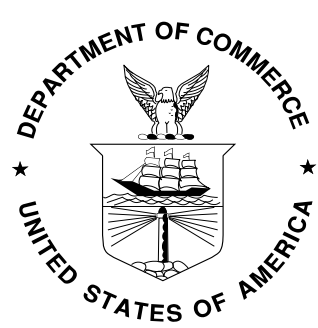

U.S. Department of Commerce

Rebecca M. Blank, Acting Secretary

National Institute of Standards and Technology Patrick D. Gallagher, Director 


\title{
Metallurgical Investigations into Corrosion Damage in Homes Constructed with Problem Drywall ${ }^{\dagger}$
}

\author{
R. E. Ricker, D. J. Pitchure, M. E. Williams, and S. A. Claggett
}

\section{EXECUTIVE SUMMARY}

The U.S. Consumer Product Safety Commission (CPSC) has received thousands of consumer reports of a particular type of drywall causing problems in homes in the United States. Many of these consumer reports blamed the presence of this malodorous "problem drywall" on corrosion failures in their heating, ventilation, air conditioning (HVAC) systems, appliances, consumer electronics, and lighting fixtures. In response, the CPSC, Sandia National Laboratories (SNL), and the National Institute of Standards and Technology (NIST) collaborated to investigate how corrosion accelerated by the presence of problem drywall could influence the reliability and functionality of fire safety systems in these homes. This report covers the metallurgical examinations associated with this investigation conducted by the Metallurgy Division of NIST.

The investigations covered in this report focused on three critical issues:

(1) the integrity of metallic structures used to contain natural gas,

(2) the reliable function of smoke detectors alarms, and

(3) the reliable function of heat sensing sprinklers.

These investigations consisted of five phases:

(1) the examination of samples removed from homes with "problem drywall" by CPSC staff and delivered to NIST for examination,

(2) the in-situ examination of metallic components in two homes constructed with problem drywall by NIST and CPSC staff,

(3) the examination at NIST of components selected during the in-situ examination of the homes with problem drywall,

(4) a collaboration between NIST, CPSC, and SNL to design, conduct, and analyze the results of accelerated corrosion tests on coupons selected to represent critical alloys and components in an environment designed to simulate approximately 40 years of exposure to polluted industrial atmospheres of the type found in homes with problem drywall, and

(5) the examination at NIST of smoke alarms and fire sprinklers that exhibited a change in performance following exposure to the accelerated corrosion testing environment at SNL.

These studies found:

(1) dark-grey and black corrosion products on the surface of alloys containing copper and silver (this includes silvered mirrors and chrome-plated brass fixtures);

(2) deposits that were identified by X-ray diffraction to be sulfides of copper and silver;

\footnotetext{
$\dagger$ The identification of any commercial product or trade name does not imply endorsement or recommendation by the authors or NIST. This report examines commercial products, but assumes that these represent typical products representative of those made by any manufacturer and that all observations are generic to all manufacturers.
} 
(3) very little evidence of attack on steel or stainless steel components;

(4) dark and opaque corrosion deposits, such that a thin film can dramatically alter appearance;

(5) a relatively small amount of attack compared to that required to compromise the structural integrity of the components examined;

(6) a relatively small amount of corrosion damage to coupons exposed to accelerated corrosion conditions designed to represent 40 years of exposure at SNL compared to that required to compromise the strength of materials in structural applications such as materials used to contain fuel gases;

(7) a failure in a microwave oven to operate due to formation and growth of silver sulfide between low-voltage control circuit contacts;

(8) similar silver sulfide deposits in the contacts for the alarm buzzer of a smoke detector that failed to produce a proper alarm in NIST function tests after accelerated aging at SNL; and

(9) no clear cause for the failure of a heat-sensing sprinkler in NIST function tests after accelerated aging at SNL.

Based on these results, it is concluded that:

(1) the corrosion damage and products found on components removed from these homes are consistent with exposure to a reduced sulfur compound such as hydrogen sulfide $\left(\mathrm{H}_{2} \mathrm{~S}\right)$;

(2) the results indicate that this corrosion damage will not compromise the strength of materials in critical structural applications such as the containment of fuel gases;

(3) the corrosion damage to coupons exposed to accelerated corrosion conditions designed to represent 40 years of exposure at SNL was small compared to that required to compromise the strength of materials in structural applications;

(4) no evidence was found of a localized form of corrosive attack on any of the components or coupons examined;

(5) there are a number of applications where a small amount of corrosion at a critical location may inhibit function such as low-voltage electrical contacts, switches, valves, seals, and this include appearance for fixtures and furnishings; and

(6) this form of attack has demonstrated an ability to get into systems where air can circulate and cause problems between contacting surfaces of the susceptible metals. 


\title{
Metallurgical Investigations into Corrosion Damage in Homes Constructed with Problem Drywall
}

\author{
August 2011 \\ R. E. Ricker, D. J. Pitchure, M. E. Williams, and S. A. Claggett \\ Materials Performance Group \\ Metallurgy Division \\ Material Measurement Laboratory \\ National Institute of Standards and Technology \\ Gaithersburg, MD 20899-8553
}

\begin{abstract}
A number of critical and noncritical life safety systems in residences are fabricated using metallic materials that are subject to corrosion. Virtually all of the metallic materials used in residential construction are subject to corrosive attack by the normal residential atmosphere, as well as the other environments they may encounter. However, under normal conditions, the corrosion of these metals progresses slowly enough that degradation does not significantly influence the function of these systems before they are replaced for other reasons. A change in the chemical composition of the atmosphere found in a residence may alter this situation, and corrosion rates could be accelerated to the point that occupant safety is compromised. The U.S. Consumer Product Safety Commission (CPSC) has received thousands of consumer reports of "problem drywall" installed in homes in the United States. Many of these consumer reports blamed the presence of this malodorous "problem drywall" on corrosion failures in their heating, ventilation, air conditioning (HVAC) systems, appliances, consumer electronics, and lighting fixtures. In response, the CPSC, Sandia National Laboratories (SNL), and the National Institute of Standards and Technology (NIST) collaborated to investigate how corrosion accelerated by the presence of problem drywall could influence the reliability and functionality of fire safety systems in these homes. This report covers the metallurgical examinations associated with this investigation conducted by the Metallurgy Division of NIST.

The investigation focused on three critical issues: (1) the integrity of metallic structures used to contain natural gas, (2) the reliable function of smoke detectors and alarms, and (3) the reliable function of heat activated fire sprinklers. Essentially, the investigation consisted of five phases: (1) the examination at NIST of samples removed by CPSC staff from homes with problem drywall, (2) the in-situ examination of metallic components in two homes constructed with problem drywall, (3) the examination at NIST of components selected during the in-situ examination of the homes with problem drywall, (4) collaboration with the CPSC and SNL to design, conduct, and analyze the results of accelerated corrosion tests on coupons selected to represent critical alloys and components in an environment simulated to represent approximately 40 years of exposure to polluted industrial atmospheres of the type found in homes with problem drywall, and (5) the examination at NIST of smoke alarms and fire sprinklers that exhibited a
\end{abstract}


change in performance following exposure to the accelerated corrosion testing environment at SNL.

The results of the examinations of components removed from problem drywall homes indicate that a chemical compound that contains reduced sulfur, such as hydrogen sulfide $\left(\mathrm{H}_{2} \mathrm{~S}\right)$, is present in these homes at concentrations significantly higher than normally found in homes in the United States. Reduced sulfur species of this type accelerate corrosion, and the alloys most affected by these species are those that contain copper and silver. Copper and copper alloys are used in homes for plumbing, fuel gas pipes, brass fittings, HVAC systems, and electrical circuits. Silver and silver alloys are used in the electrical circuits of some consumer electronics, as well as in mirrors, jewelry, fixtures, tableware, and flatware.

While all types of metals were examined in the homes with problem drywall, only metals and alloys containing copper and silver showed evidence of accelerated attack. These metals and their alloys all showed a dramatic decrease in their luster, and in most cases, were covered with a dark opaque layer of corrosion products. In all cases where measurements were made, this layer was thin compared to the thickness of critical structural materials (i.e., fuel gas pipes and fittings). Of critical concern to the long-term reliable function of systems is the possibility of localized corrosive attack. Localized forms of corrosion, such as pitting, crevice corrosion, and stress corrosion cracking, enable corrosion to penetrate faster and deeper into a critical member than a uniform general attack. In addition, localized forms of attack complicate the prediction of service lifetimes or failure rates. No evidence of any localized forms of attack has been found on any of the collected samples examined or components examined after testing, to date. All results are consistent with a general attack form of atmospheric corrosion that should progress in a uniform and relatively predictable manner.

At the Facility for Atmospheric Corrosion Testing (FACT II) at SNL, the long-term effects of exposure to atmospheric conditions of this type were evaluated via accelerated exposure tests. New corrosion coupons, smoke alarms, and fire sprinklers were exposed to an accelerated corrosion environment that the literature and the experience of SNL staff at FACT II indicated was the most representative accelerated corrosion environment for this type of atmosphere. The results of the examinations of components exposed to this corrosive environment showed no evidence of a localized corrosion form of attack on any of these samples. The NIST Fire Research Division conducted functional tests on the smoke alarms and fire sprinklers, and the results of these tests are reported separately. Smoke alarms and fire sprinklers that exhibited degradation in performance in functional testing after exposure were transferred to the Metallurgy Division for analysis. The results of these analyses and the analysis of the corrosion coupons mass changes are presented in this report. 


\title{
Metallurgical Investigations into Corrosion Damage in Homes Constructed with Problem Drywall ${ }^{\dagger}$
}

\author{
August 2011 \\ R. E. Ricker, D. J. Pitchure, M. E. Williams, and S. A. Claggett \\ Materials Performance Group \\ Metallurgy Division \\ Material Measurement Laboratory \\ National Institute of Standards and Technology \\ Gaithersburg, MD 20899-8553
}

\section{INTRODUCTION}

Metallic materials used in home construction are subject to corrosive attack by the normal internal atmosphere of homes, as well as other environments they may encounter. The corrosion resistance of the metals in these environments is a major factor in determining the normal deterioration of the performance of household systems, appliances, and consumer goods. This includes the systems responsible for safely providing the home with utilities, such as electricity and natural gas, in addition to systems that protect occupant safety, such as smoke alarms and fire sprinklers. Whenever any household system deteriorates more rapidly than normal, there is a high probability that accelerated corrosion is responsible. Also, whenever there is evidence of accelerated corrosion to noncritical systems in a home, there is good cause for concern about the reliable function of the life safety critical systems throughout the home constructed with similar metals and alloys.

Of immediate concern is the significant number of reports of accelerated deterioration due to corrosion in homes constructed with a certain type of drywall. This "problem drywall" generated many complaints from homeowners about accelerated corrosion that the U.S. Consumer Product Safety Commission (CPSC) became concerned that this problem drywall contains chemical species that make the internal atmosphere of homes more corrosive. The CPSC also became concerned that this could accelerate the deterioration of systems that perform critical life safety functions to the point that they would fail to perform their functions satisfactorily in the future. As a result, the CPSC instituted a multitasked investigation to look at problem drywall and how it influences the performance of critical household systems. As part of this investigation, the Material Measurements Laboratory (MML) of the National Institute of Standards and Technology (NIST) became involved, through an interagency agreement, to examine metallic samples removed from service in homes constructed using problem drywall.

\footnotetext{
$\dagger$ The identification of any commercial product or trade name does not imply endorsement or recommendation by the authors or NIST. This report examines commercial products, but assumes that these represent typical products representative of those made by any manufacturer and that all observations are generic to similar products by all manufacturers.
} 
The objective of these examinations is to identify potential corrosion-related failure modes, corrosion product chemistry, and potential chemical reactions.

As a result, the CPSC, Sandia National Laboratories (SNL), and the National Institute of Standards and Technology (NIST) collaborated in an investigation to understand how corrosion accelerated by the presence of this problem drywall could influence the reliability and functionality of fire safety systems, as well as gas components in these homes. This report covers the metallurgical examinations associated with this investigation that were conducted by the Metallurgy Division of NIST.

This investigation focused on three critical issues: (1) the integrity of metallic structures used to contain natural gas, (2) the reliable function of smoke alarms, and (3) the reliable function of heat activated fire sprinklers. This investigation consisted of essentially five phases: (1) the examination at NIST of samples removed by CPSC staff from homes with problem drywall, (2) the in-situ examination of metallic components in two homes constructed with problem drywall, (3) the examination at NIST of components selected during the examination of the in-situ homes with problem drywall, (4) collaboration with the CPSC and SNL to design, conduct, and analyze the results of accelerated corrosion tests on coupons selected to represent critical alloys and components in an atmosphere designed to simulate 40 years of exposure to polluted industrial atmospheres of the type found in homes with problem drywall, and (5) the examination at NIST of smoke alarms and fire sprinklers that exhibited a change in performance following exposure to the accelerated corrosion testing environment at SNL.

\section{LABORATORY EXAMINATIONS OF SAMPLES FROM HOMES}

\section{A. Sample Selection and Delivery}

Representative samples of components with corrosion damage from homes constructed with problem drywall were collected, transported, and delivered to NIST by CPSC staff. These samples were received on September 28, 2009, and immediately cataloged. The samples received consisted of a number of lengths of copper tubing used as natural gas supply lines and two air conditioner heat exchanger coils.

\section{B. Visual Examination and Photography}

The lengths of copper tubing were discolored to varying degrees. This discoloration, which is illustrated in Figure 1, was found to be due to the presence of a thin, adherent layer of a black substance. This is clearly illustrated in Figure 2, where the sample number has been scribed into the sample exposing fresh bare copper. While this black film adhered to the surface, physical contact would result in the transfer of a small quantity of a fine black powder from the film. In some cases, the discoloration was found to be very uniform, but in other cases it was irregular. The extent of discoloration varied with the thickness of the layer. 

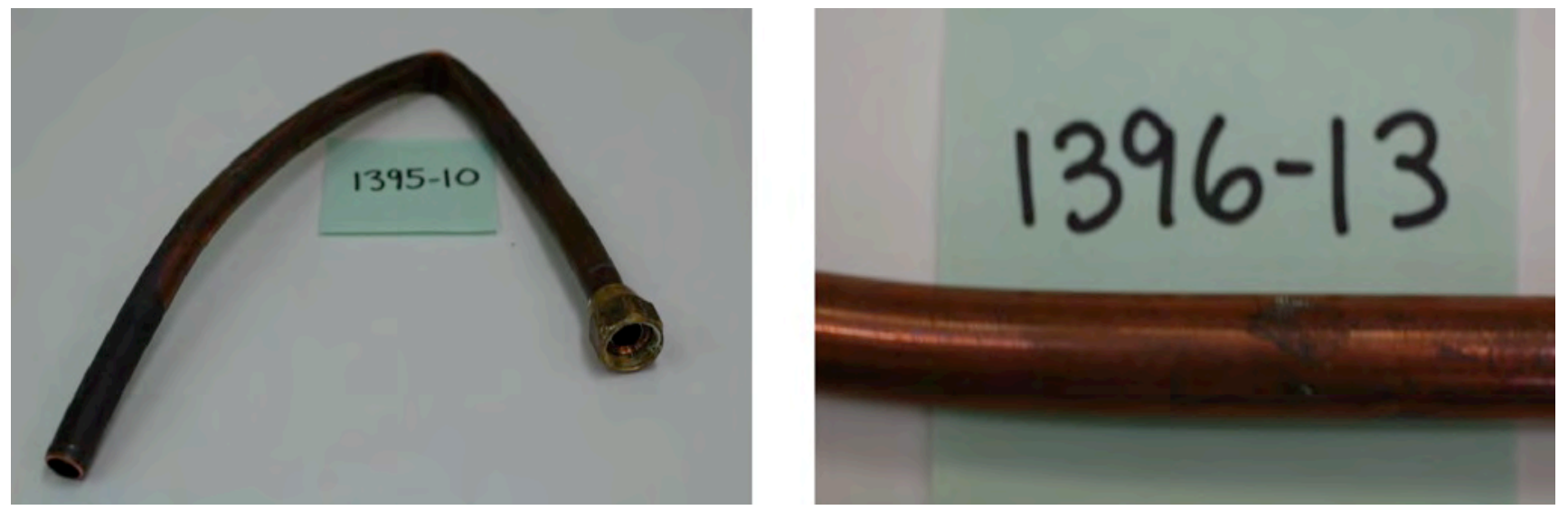

Figure 1 - Photographs of two representative samples of $\mathrm{Cu}$ fuel gas distribution tubing.

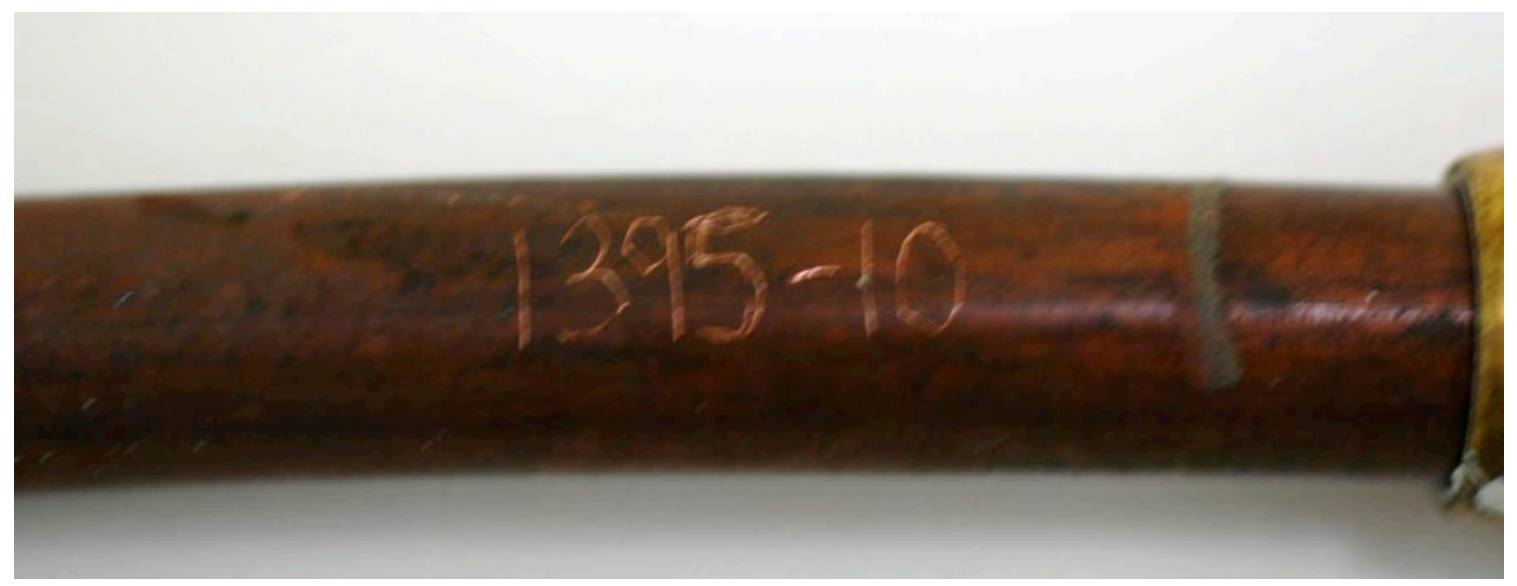

Figure 2 - Scribe marks illustrating the contrast between the color of bare copper and a sample of copper natural gas line tubing.

The air conditioner evaporator coils were also examined, Figure 3. From the two coils in this figure, all exposed copper surfaces appear to have turned dark. These coils are constructed out of parallel lines of copper tubing placed through thin sheets of aluminum (Al) that serve as the heat transfer fins. The copper tubing is linked by soldered U-bends to the ends of adjacent lengths of copper tubing. The end plates that hold this assembly in place are made out of galvanized steel. Copper manifolds and valves complete the assembly. Figure 4 is a close-up of the end plates and the U-bend region. In this figure, brown and orange corrosion products can be seen on the galvanized end plates, while black and green corrosion products can be seen on the copper tubing. The normal patina that forms on copper in the cyclically wet and dry environment of an air conditioner evaporator coil would be expected to contain copper (I) or copper (II) ions in oxides (black to brownish-red), carbonates (green to blue), sulfates (bright blue), and chlorides (greenish white to blue-green). ${ }^{1,2}$ Again, the black color was found to be due to the presence of a thin layer of black powder. 


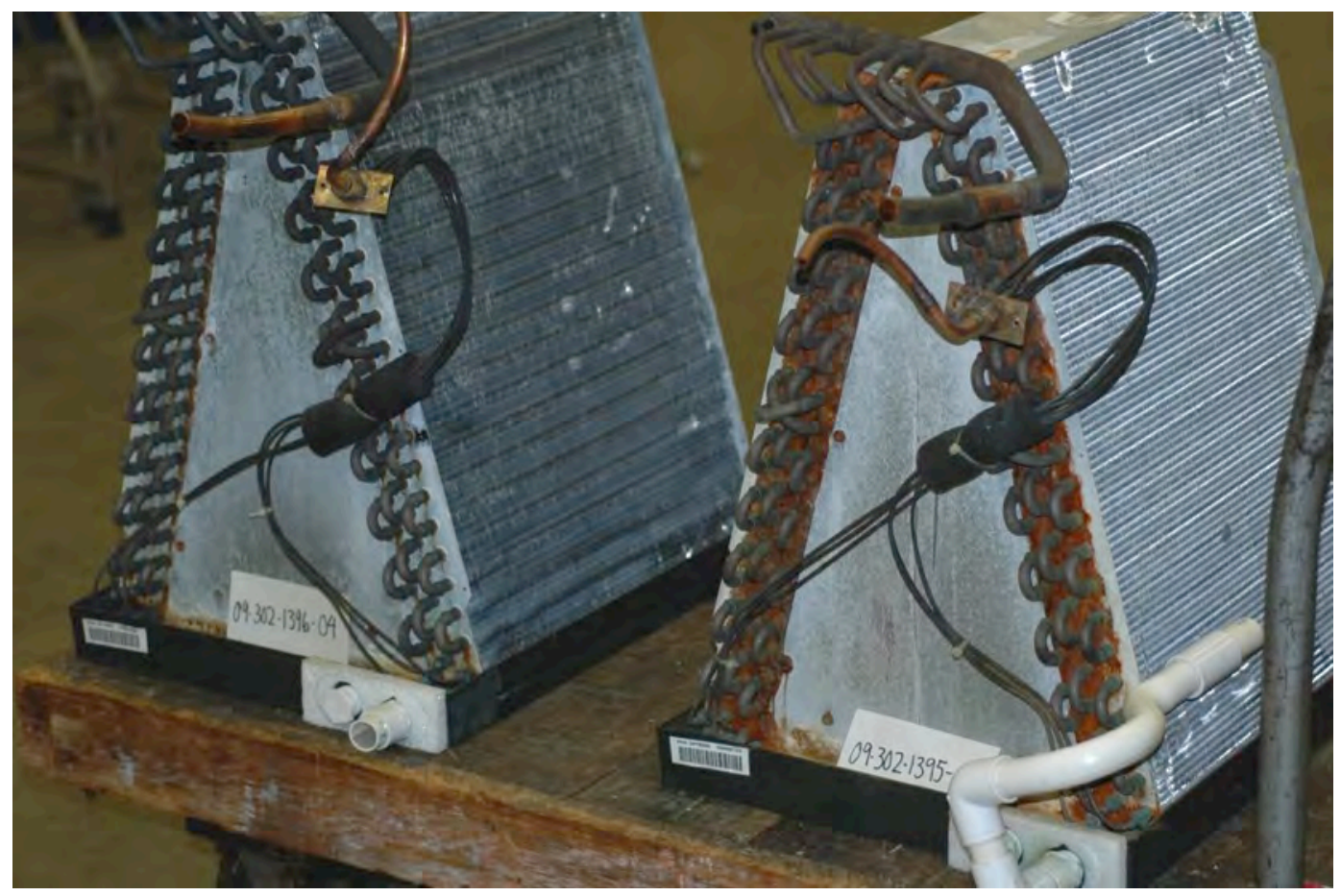

Figure 3 - Photograph of the two air conditioner evaporator coils showing the black discoloration of the copper U-bends and corrosion of the end plate.

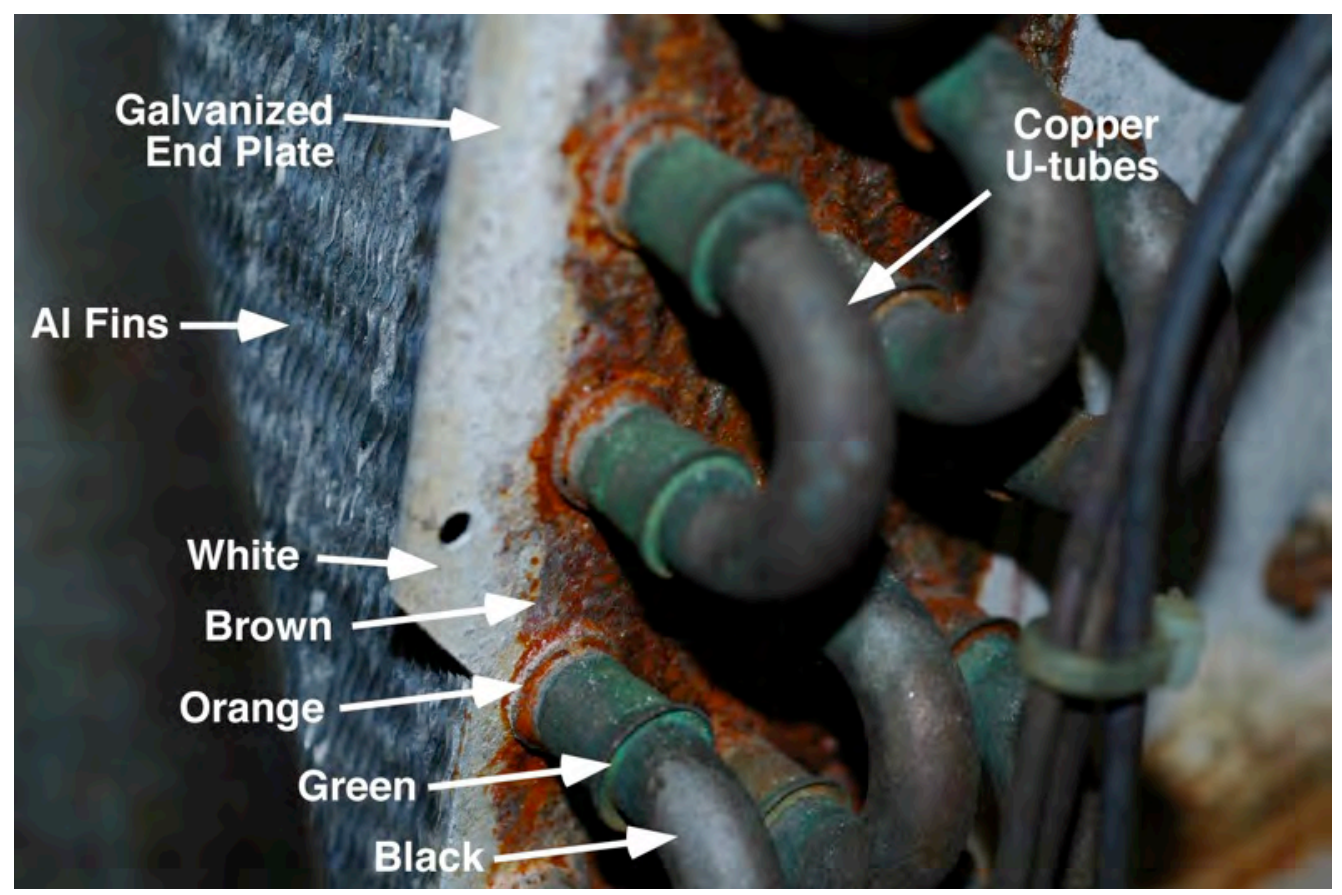

Figure 4 - Close-up photograph of the U-bends and end plate of an air conditioner evaporator coil showing that there appears to be five colors associated with the corrosion products: white, brown, orange, green, and black. 


\section{Identification of the Black Corrosion Product by X-Ray Diffraction}

The black substance observed on the surfaces of the copper components was identified by Xray diffraction. This was accomplished by scraping the black substance from the surface of one of the samples of copper natural gas line tubing using a razor blade. The powder removed in this manner was placed on double stick tape and attached to a glass slide, as shown in Figure 5. A powder diffraction pattern was then obtained from this sample of scrapings using a Siemens D500 X-ray diffractometer with a $\mathrm{Cu} \mathrm{K}_{a}$ radiation source operated at $40 \mathrm{kV}$ (kilovolts) and 30 $\mathrm{mA}$ (milliamperes) using a step size of 0.03 degrees, and a dwell time of 5 seconds (s).


Figure 5 - Photographs of the scraped copper natural gas supply line (a) and the slide holding the sample for X-ray diffraction (b).

Figure 6 shows the results of these measurements in red along with the peak locations in black for copper metal (Figure 6a), copper (I) oxide (Figure 6b) and copper (I) sulfide (Figure $6 c$ ) as listed in the International Crystal Structure Database (ICSD) for the phase of copper sulfide known as digenite $\left(\mathrm{Cu}_{1.80} \mathrm{~S}\right.$ or $\left.\mathrm{Cu}_{9} \mathrm{~S}_{5}\right)$. This figure shows that peaks corresponding to all three of these phases are present in the sample of scrapings from the surface of the copper natural gas supply line. Given that the sample was collected by scraping the surface of copper metal with a sharp razor blade, the peaks for copper and copper oxide were expected because copper is a soft metal compared to the steel of the razor blade, and it will normally form copper oxide when exposed to air. The third phase, copper sulfide $\left(\mathrm{Cu}_{2} \mathrm{~S}\right)$, is not a typical atmospheric corrosion product because the concentration of the reduced sulfur species, such as $\mathrm{H}_{2} \mathrm{~S}$, required to form this product, is usually very low under normal indoor atmospheric conditions. ${ }^{13-5}$ Figure 7 is a summary of the XRD results showing that all but two small peaks, indicated by question marks, are accounted for by these three phases. 

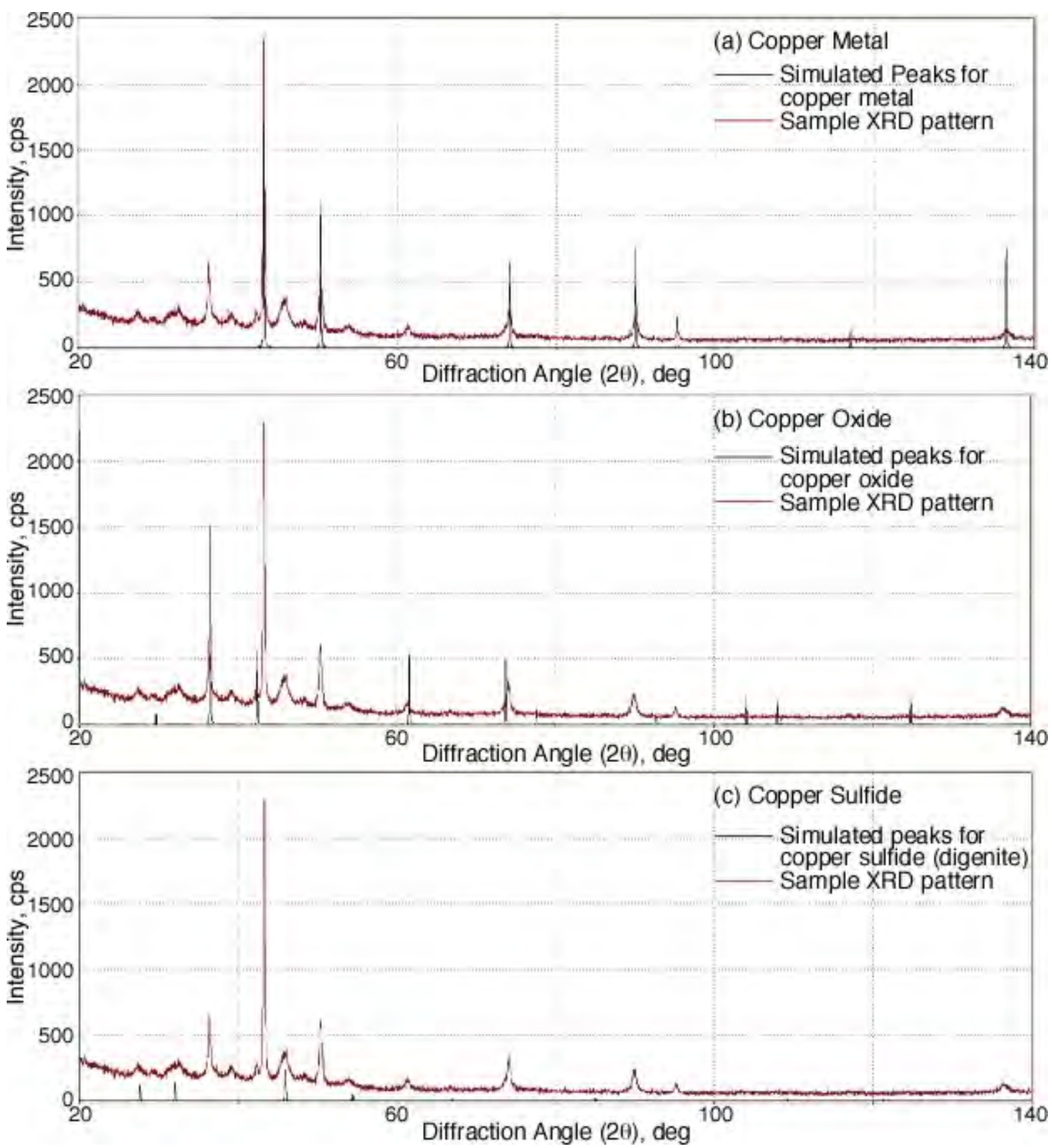

Figure 6 - Measured X-ray powder diffraction patterns for the sample of corrosion products scraped off a $\mathrm{Cu}$ natural gas supply line in red compared with simulated patterns for specific structures in black (simulated peaks do not contain background noise): (a) $\mathrm{Cu}$ metal, (b) copper (I) oxide (ICSD \#38233), and (c) the copper (I) sulfide phase digenite $\left(\mathrm{Cu}_{9} \mathrm{~S}_{5}\right.$ ) (ICSD \#95395). 


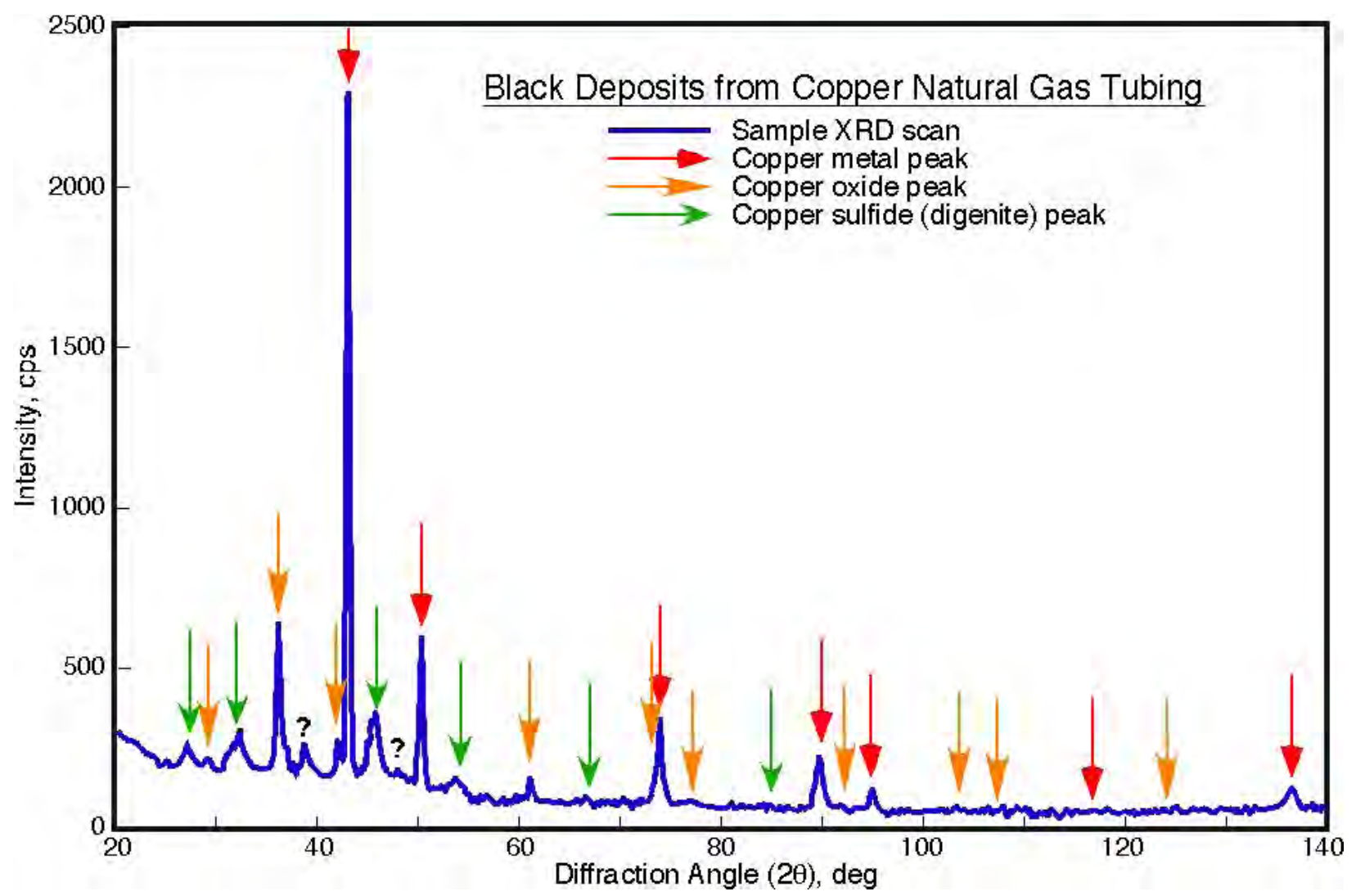

Figure 7 - Summary of peaks found in the corrosion product sample and their identification for showing that only two small peaks were unidentified by the three phases.

\section{Air Conditioner Evaporator Coil Leak Testing}

Leak testing was performed on the air conditioner heat exchange coils by attaching airtight fittings to the ends of the copper lines and connecting these to a helium gas detector. The inside of the coil was evacuated, and helium gas passed over different regions of the coils. No leaks were found by this method. Then the coils were pressurized with helium, and a solution of soapy water was squirted onto different regions of the coils. This method also failed to find any leaks in these coils. These coil samples had not been reported to be leaking refrigerant when installed in the house.

\section{E. Air Conditioner Evaporator Coil Sectioning}

To evaluate the possibility of corrosion damage occurring between the aluminum heat transfer fins and the copper tubing inside them, the heat exchanger unit was sliced with a band saw, as shown in Figure 8, to expose these internal surfaces for examination of the copper. No evidence of localized attack was found, and visual inspection did not detect a black corrosion product layer between the aluminum fins and the copper tubes of the evaporator coil. 


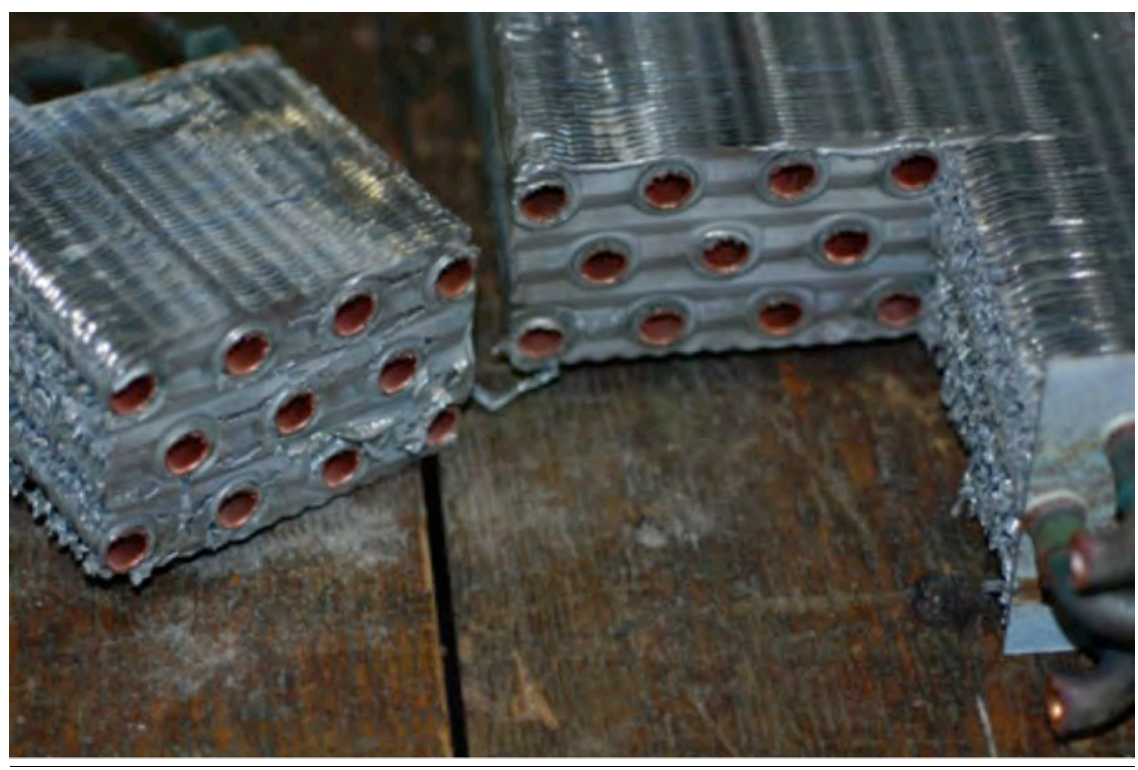

Figure 8 - Air conditioner evaporator coil after slicing to allow for examination for corrosion damage between the aluminum sheets and the copper tubing.

\section{F. Measurement of Corrosion Product Layer Thickness}

The thickness of the black corrosion product on a fuel gas supply tube was measured using optical microscopy of samples prepared in cross section. For this analysis, samples of natural gas supply lines were cut, mounted in epoxy, and polished, using standard metallurgical practice, exercising care to maintain the edge of the sample with the corrosion products in place. Figure 9 shows optical micrographs of this sample, where the corrosion product layer varied from (5 to $10 \pm 0.5) \mu \mathrm{m}$ thick.
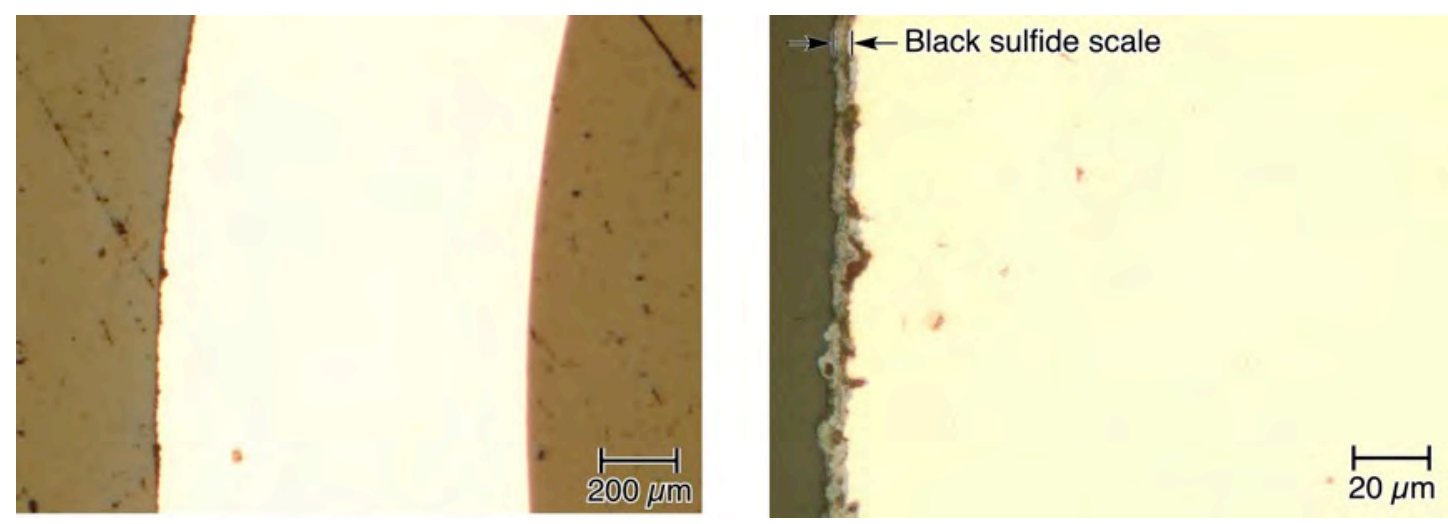

Figure 9 - Optical micrographs of the wall of a copper natural gas supply line and the corrosion product layer at two magnifications. 


\section{EXAMINATIONS OF HOMES AND SELECTED SAMPLES}

\section{A. Sample Selection and Delivery}

Two members of the NIST Metallurgy Division staff accompanied CPSC staff to Florida for the identification and selection of the second group of representative samples of corrosion damage in homes constructed with problem drywall that were in the process of undergoing remediation by the homebuilder. The team visited two homes that were at different stages of the remediation process. In one case, all of the drywall had been removed, and all of the appliances had been uninstalled and were in the garage awaiting removal from the premises. In the other case, the appliances and drywall were in the process of being uninstalled. The objective of this sample selection process was not just to identify and select the best samples, but also to learn as much as possible about the exposure conditions, corrosion damage, and the impact of the corrosion damage on the function of household systems from the in-situ examinations and through discussions with the home builder and remediation contractor staff present. Sample selection emphasized systems with metallic structures or components that have the potential for corrosion damage to compromise occupant safety. However, non-safety-related systems were also included in the sample collection process because understanding failure mechanisms in these systems that are installed in the same indoor atmospheric environment will enable understanding of how corrosion might, or might not, cause failure in the systems that influence occupant safety.

\section{B. Home Inspections}

Because the emphasis was on safety-related systems, the natural gas supply systems and appliances were examined first. Figure 10 shows the natural gas meter and inlet on the outside of one of the homes. No evidence of any corrosion damage beyond that normally expected for exposure to the outdoor atmosphere in Florida can be seen in Figure 10. Figure 11 shows the stainless steel flex tube used to connect the water heater to the gas distribution pipe. The Figure shows very little evidence of corrosion, while the outside of the brass fitting on the end is covered with a dark corrosion product. The brass visible on the inside of this fitting indicates the original color of this fitting. Figure 12 shows one of the wall electrical receptacles. As is typical in homes made with problem drywall, the bare copper ground wire is covered with a thin uniform black film of corrosion products that is so uniform that it almost appears as if the wire were painted black or is covered with a thin layer of electrical insulation. Figure 13 shows the HVAC evaporator coil in a garage after removal of the side cover, and Figure 14 shows the corrosion damage in the attic unit from the same home. Both units show considerable discoloration of the copper tubes, indicative of the reaction of copper with a reduced sulfur species similar to that shown in Figures 6 and 7. 


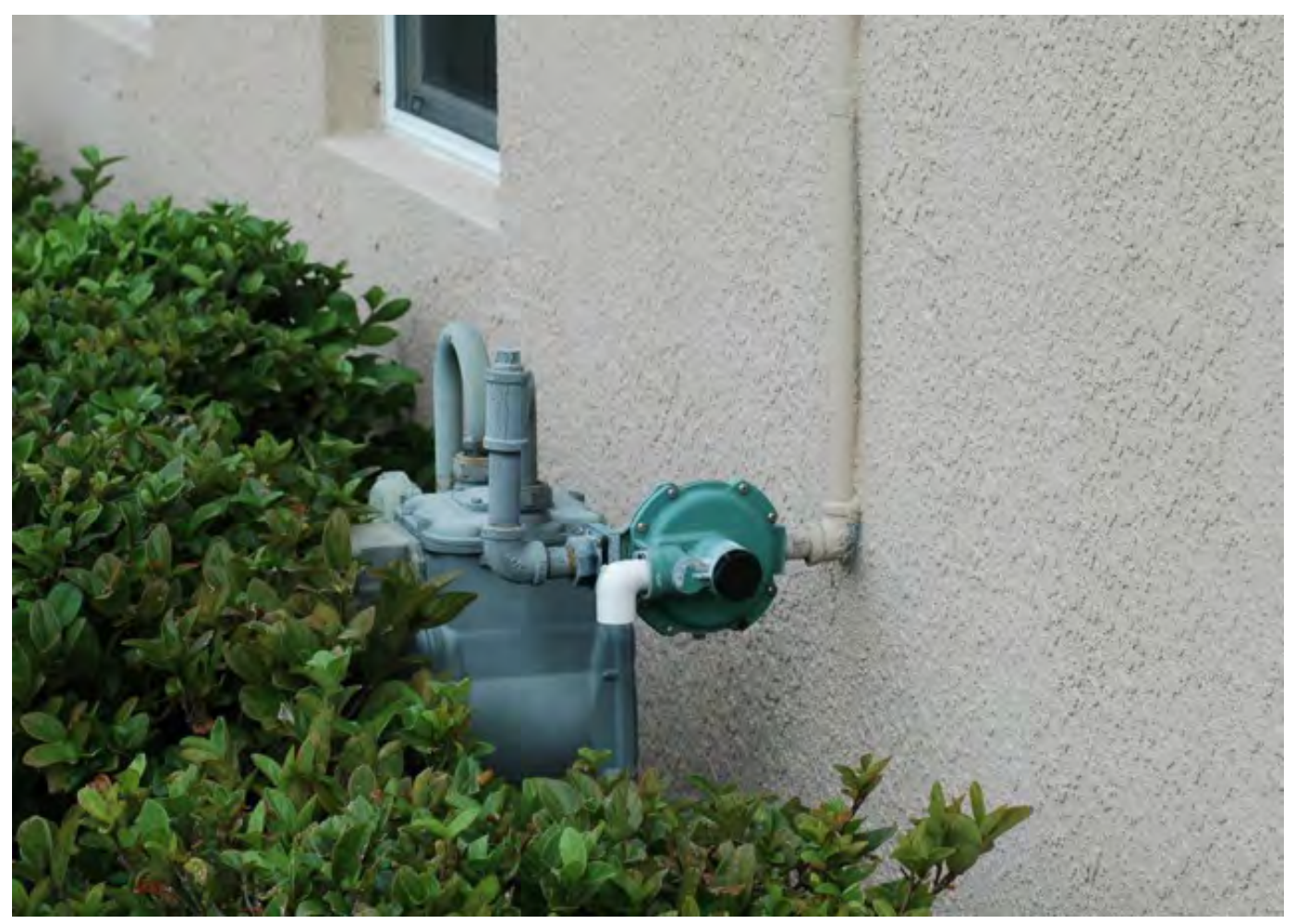

Figure 10 - Gas meter on the outside of a problem drywall home.

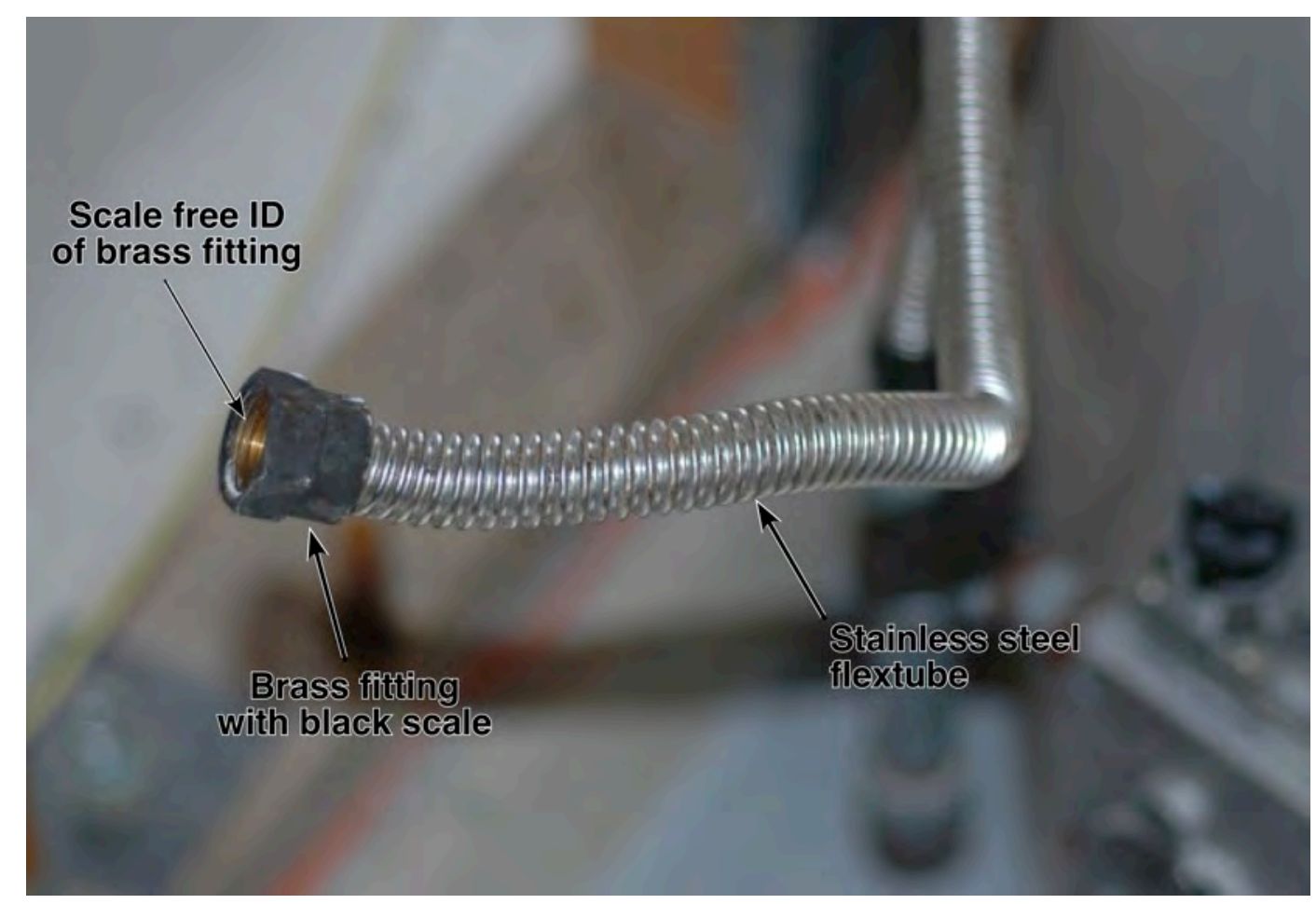

Figure 11 - Stainless steel fuel gas supply tube for the water heater. Note the contrast in the color between the inside and the outside of the brass fitting on the end. 


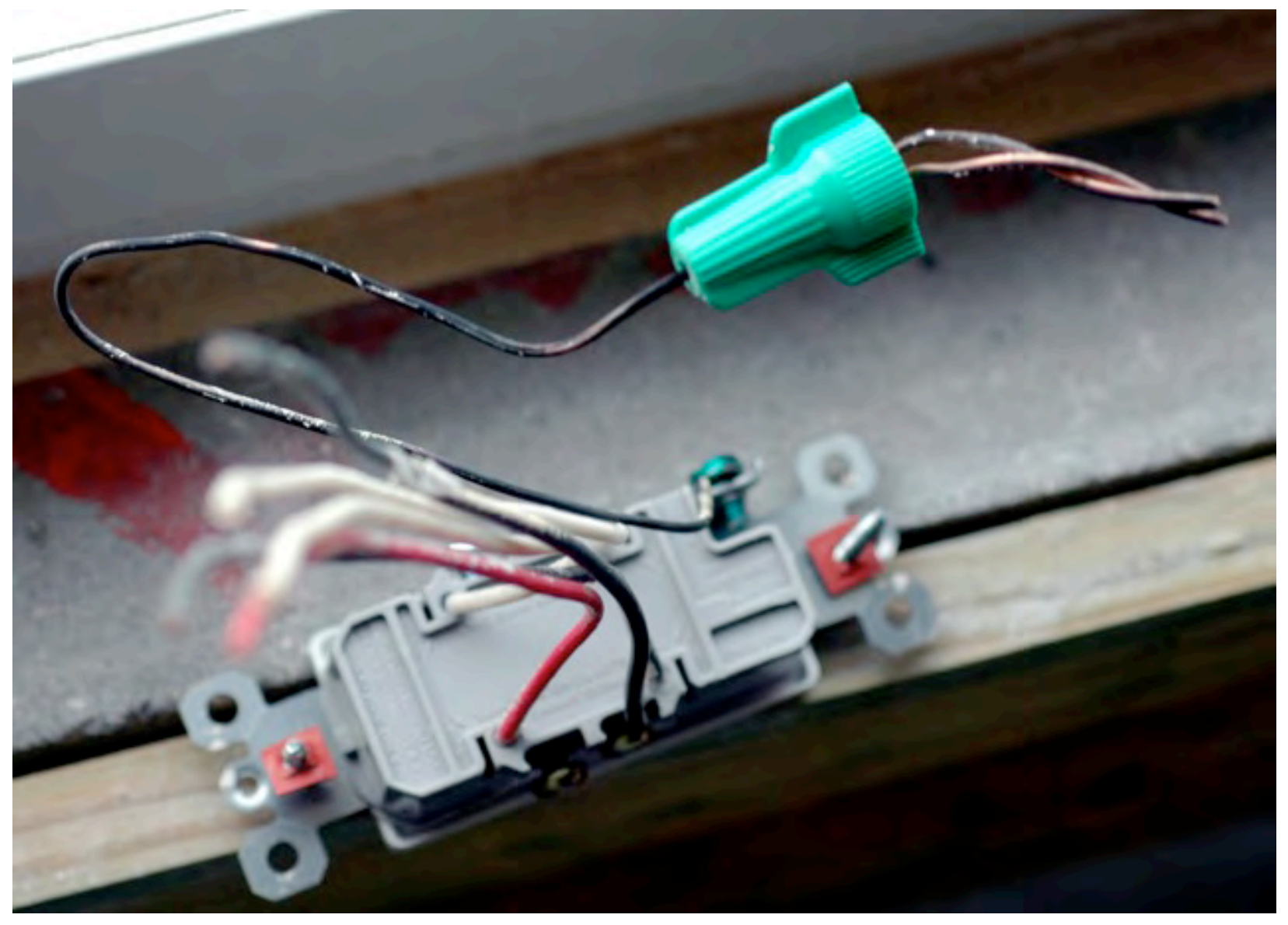

Figure 12 - Electrical wall receptacle in a home with problem drywall showing the characteristic black deposits on the bare copper ground wire.

\section{Heating, Ventilation, and Air Conditioning (HVAC) Systems}

The homebuilder told NIST staff that both homes had experienced trouble repeatedly with the HVAC systems, which HVAC service providers attributed to loss of coolant pressure due to corrosion of the evaporator coil (A-coil). It was also reported that total replacement of the evaporator coil frequently was employed as a remedy and that both of the homes examined had their evaporator coils replaced at least once. However, these reports and the operational history of these units could not be documented, and the actual working status of the systems at the time of the NIST inspection could not be determined unequivocally. The evaporator coil shown in Figure 13, suspected to have failed in service, was tagged and shipped to NIST for laboratory examination. At NIST, the coil was pressurized and leak-tested, as shown in Figure 15. No evidence of leaking was detected, and no loss of pressure was observed. Therefore, it is concluded that either: (i) this unit was not leaking in service, or (ii) the leak was not in the evaporator coil but in a connection or section of the pressure boundary not included in this sample. Therefore, no further examinations were conducted on this unit. 


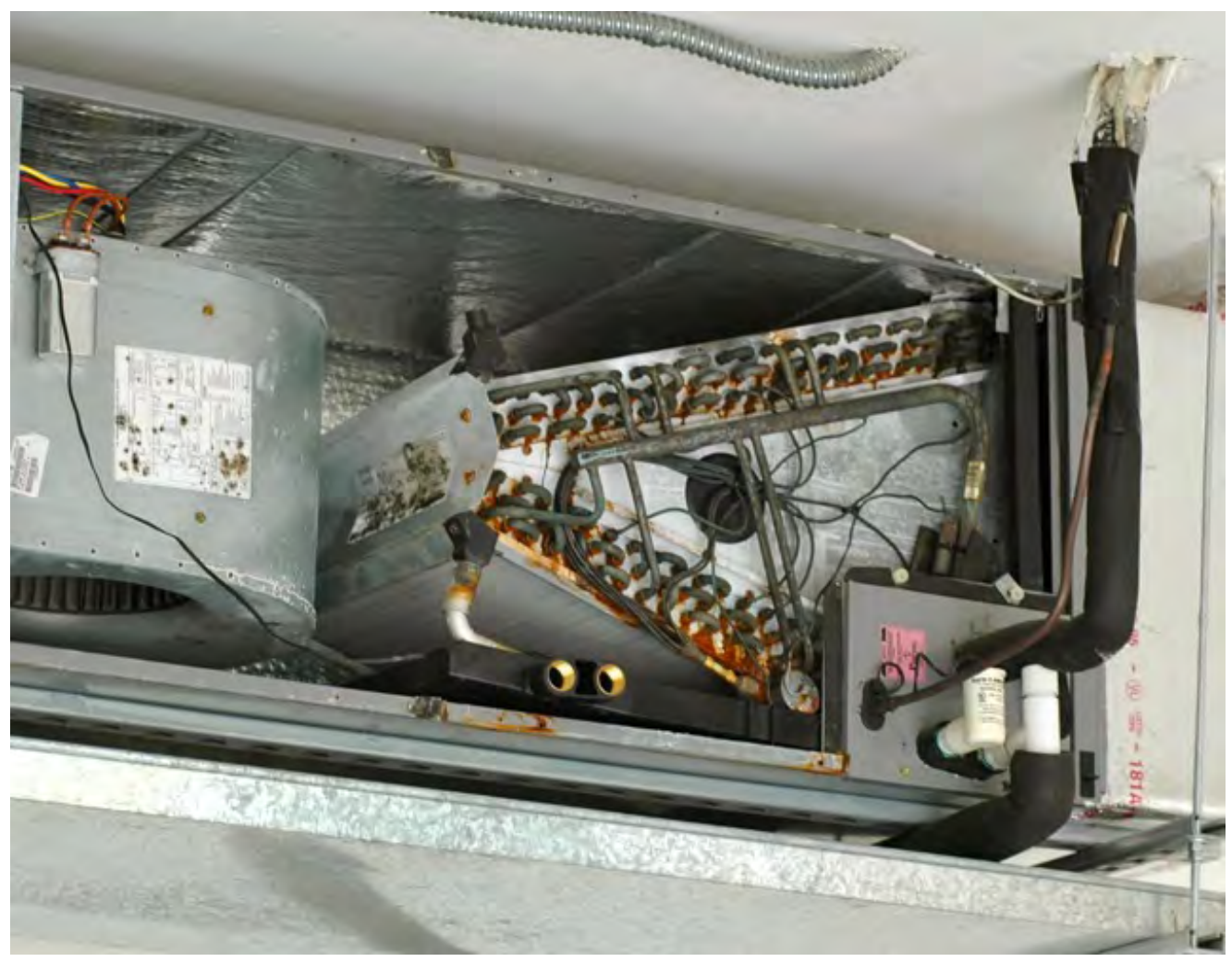

Figure 13 - HVAC unit in the garage of a problem drywall home.

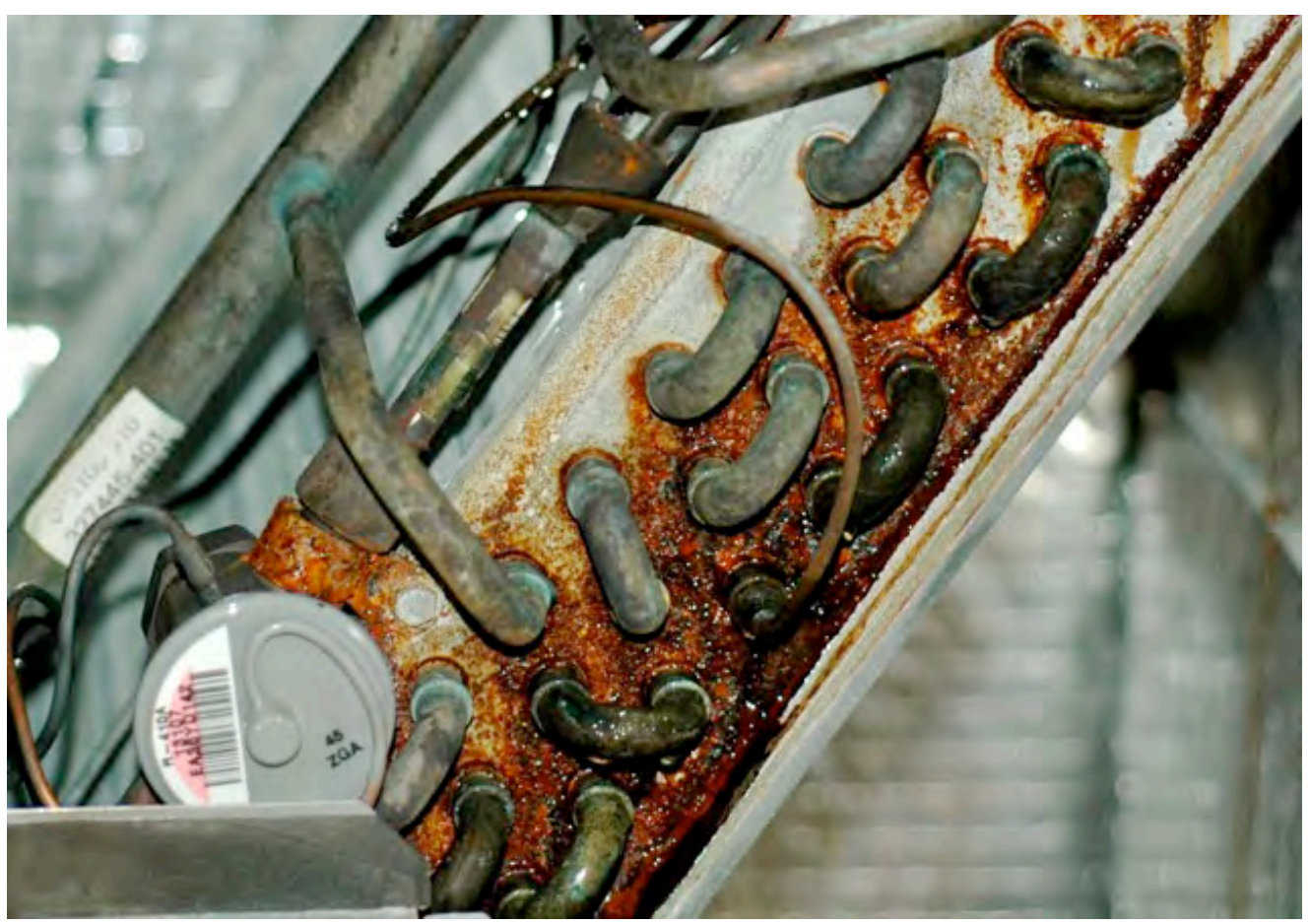

Figure 14 - HVAC unit in the attic of a home with problem drywall. 


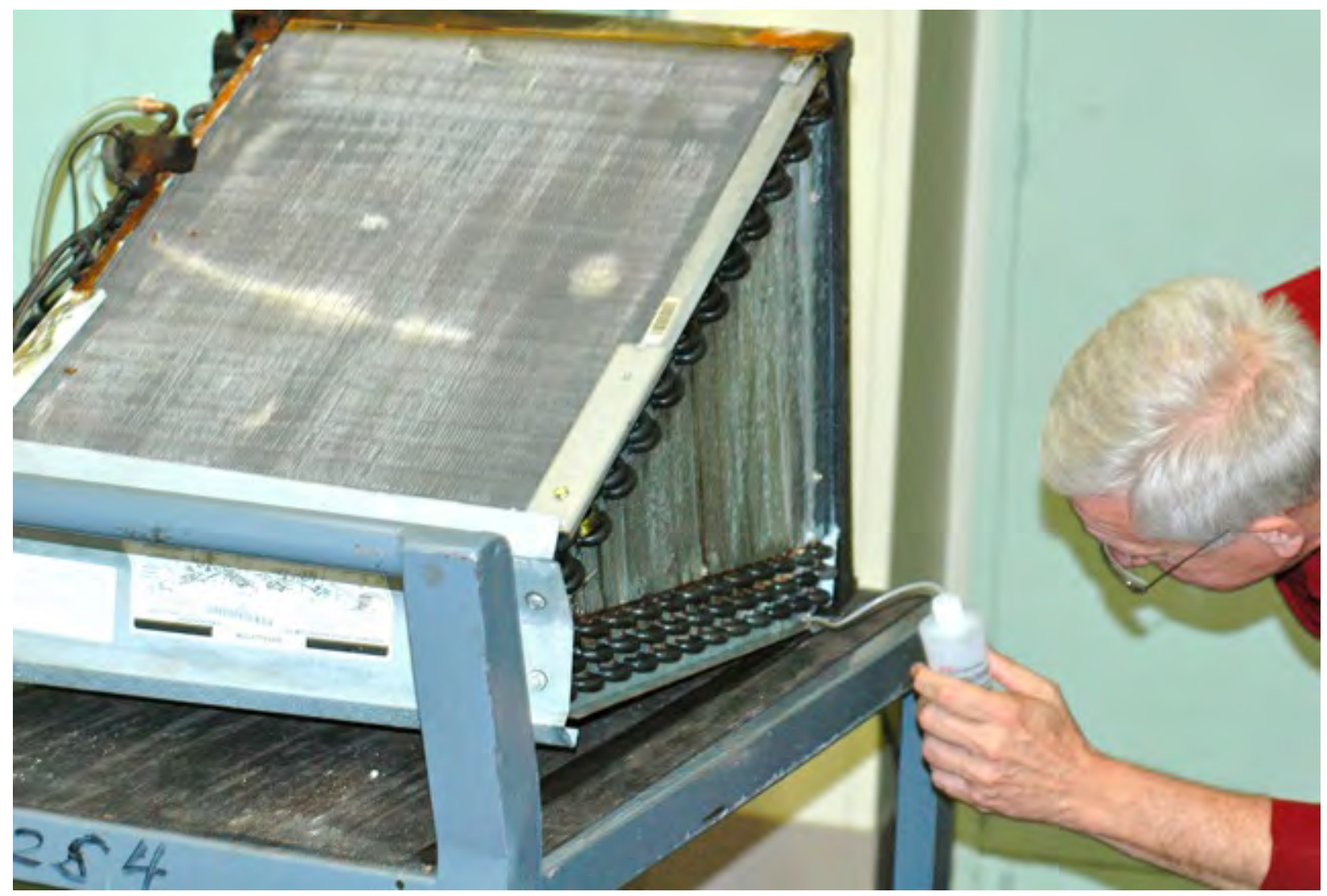

Figure 15 - The garage HVAC unit shown in Figure 13 undergoing leak testing in the metallurgy laboratory at NIST.

\section{Microwave Oven}

During the visit, NIST staff was told that the occupants of these homes reported numerous cases of consumer electronics failing to operate properly. These reports seemed to indicate that systems whose function relied primarily on printed circuit boards (PCBs) and pushbutton controls were more susceptible to these premature failures than systems that used point-to-point wiring, such as furnaces, stoves, ovens, and cook tops. Microwave ovens fit this profile and are one of the appliances reported to be susceptible to premature failures. In response to questions about the nature of these failures, NIST staff was told that a microwave oven would appear functional but would not respond to commands entered on the front panel control module. It was also reported that the failure of other consumer electronics occurred in a similar manner. Because microwaves are constructed largely with PCBs, use pushbutton controls, frequently are placed against drywall, and operate with cooling fans that draw potentially corrosive air by the electronics, it is not surprising that these systems would be among the most susceptible if there is a PCB or flat panel pushbutton-related failure mode induced by problem drywall emissions. The possibility that the same failure mechanism may operate in fire safety-related systems that use PCBs and low-voltage control circuits was deemed sufficient to warrant the acquisition and examination of a representative sample. As a result, a wall-mounted microwave oven that was 
reported to have failed to operate properly in one of the Florida homes was tagged and shipped to NIST for examination in the metallurgy laboratories.

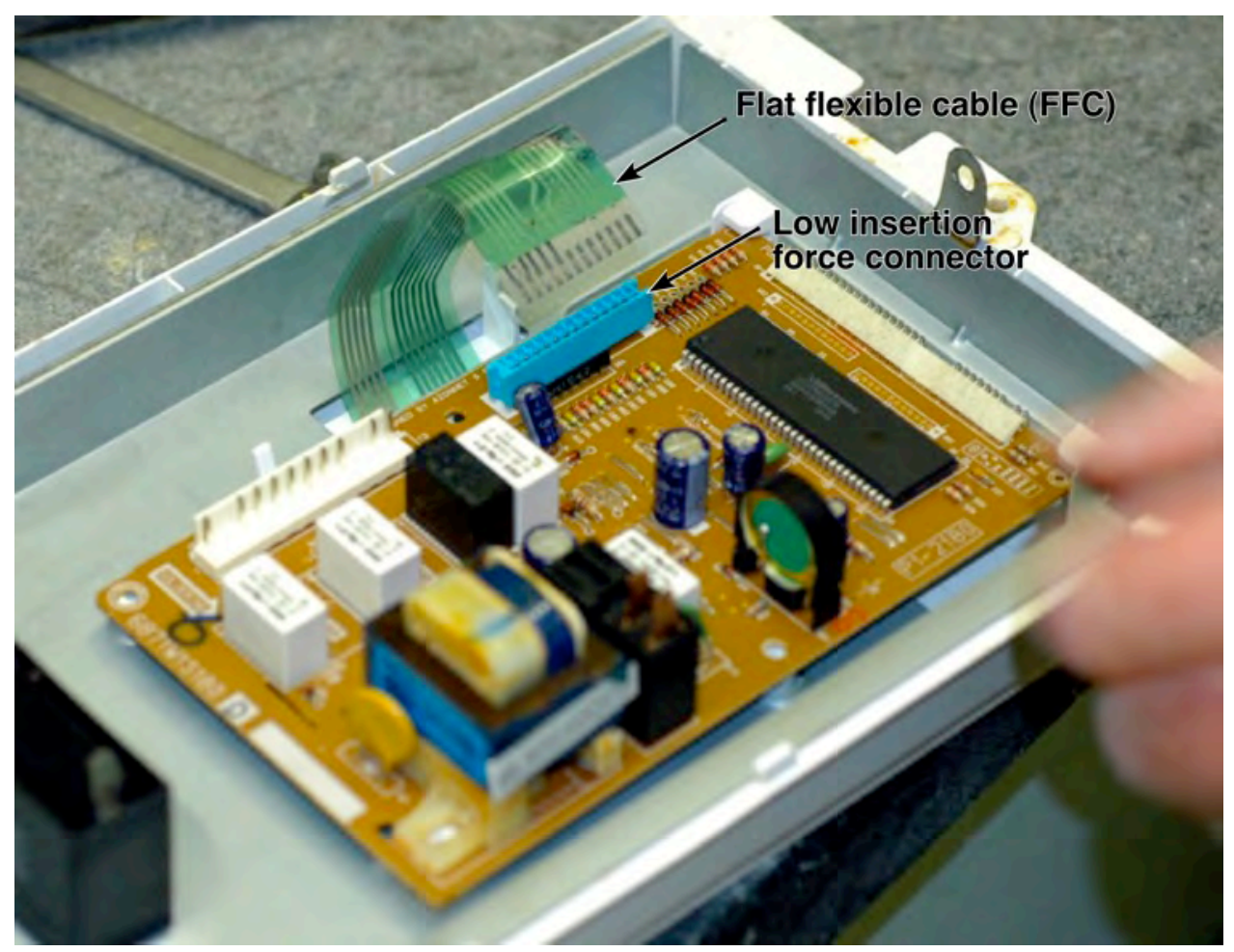

Figure 16 - Removal of the control module of the microwave oven.

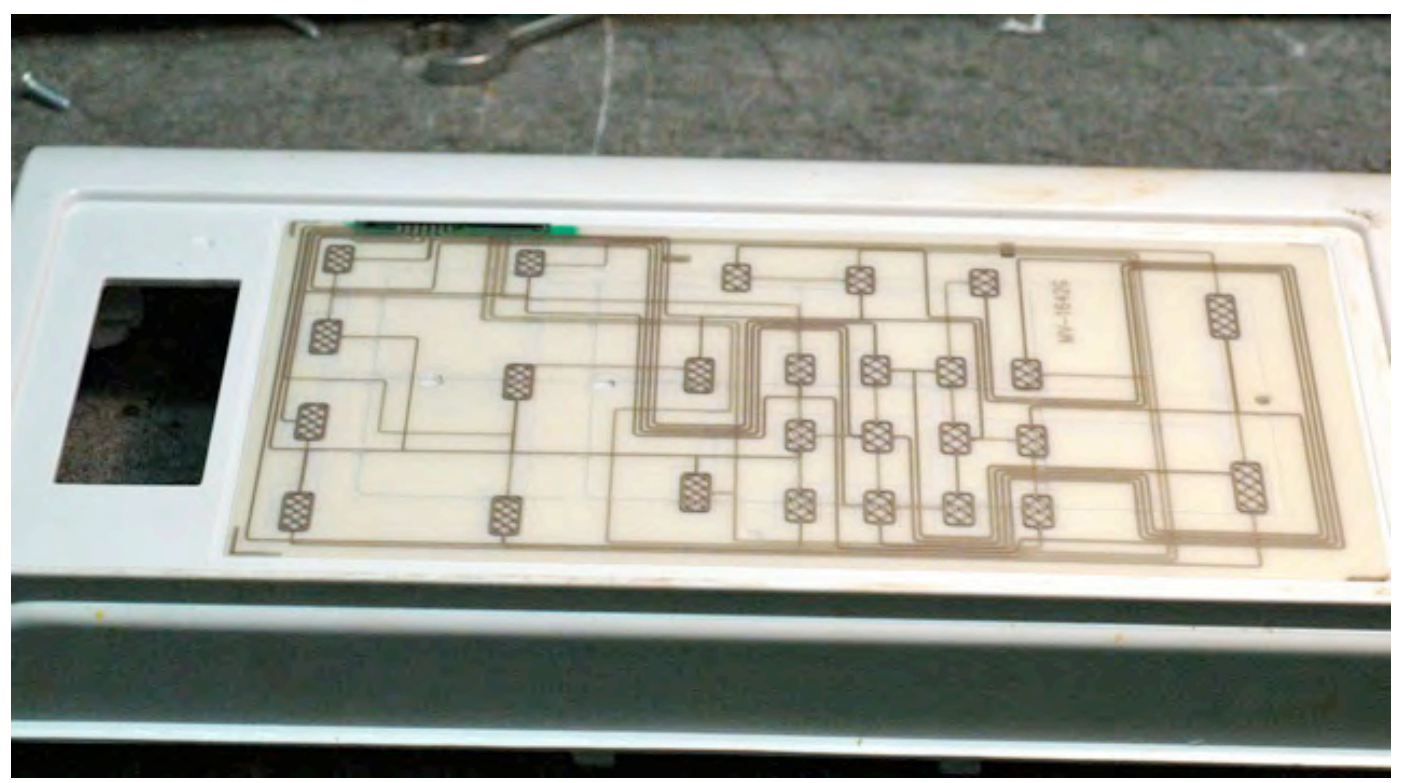

Figure 17 - Pushbutton controls with cover removed. 
After arrival at NIST, the microwave oven was plugged into an electrical outlet, and it went through its self-checks in a perfectly normal fashion. However, when NIST staff attempted to operate the microwave oven, it failed to respond to any user pushbutton commands. The team concluded that the power supply and related power systems were functioning normally and that the failure was in the low-voltage control circuits or the user pushbuttons. Because pushbuttons rely on making surface contact between metallic conductors, and because corrosion products are usually poor conductors of electricity, corrosion of the pushbutton contacts was the first failure mode hypothesis. As a result, the flat, front panel display and pushbuttons were removed (Figure 16) and examined (Figure 17). There was no immediately obvious evidence of corrosion damage to the buttons that was sufficient to cause these systems to fail, as shown in Figure 17. However, corrosion was found on the silver contacts of the flat flexible cable (FFC) contacts that are inserted into the low-insertion force connector between the flat panel pushbuttons and the microwave oven.

The FFC plug was cut from the pushbutton unit and examined macro- and microscopically. Figure 18 shows a macroscopic photograph of this connector, indicating that almost the entire contact area of each silver FFC contact is covered with a layer of dark corrosion products, and only a small spot in the middle of each contact appears to be free of these deposits. Figure 19 is an optical micrograph that shows the black deposits on the silver connector of the flat flexible cable at the connector contact area and the scratches generated when the cable was unplugged. The team hypothesized that corrosion between the contacts of the low-insertion force FFC plug and the copper contacts of the receptacle could be responsible for the failure of the unit to respond to any pushbutton commands. To determine which hypothesis was correct, the pushbuttons were connected to a resistance meter and operated. All of the pushbuttons immediately closed the circuit when pushed in a normal manner. All pushbuttons were operated numerous times, and not a single indication of any difficulty in achieving closed-circuit conditions was observed. Since the push buttons are encased between layers of polymeric film, it is not surprising that they should experience less corrosion damage than the freely exposed silver contacts of the FFC plug. However, the propagation of the corrosion between the contacts in the FFC low-insertion force connector is less obvious. As a result, the low extraction force FFC connector was reassembled, mounted in clear epoxy, and cross-sectioned for optical microscopy. Figure 20 shows the FFC low-extraction force connector in cross section. In this figure, the thin layers of corrosion products are just barely visible on the connecting faces of the contacts. The corrosion product will initially grow on the copper and silver surfaces openly exposed to air with the atmospheric contaminant produced by the drywall. The corrosion product that forms will be porous and will require more volume than the metal it replaces. ${ }^{6}$ When this product grows at the point where the contacts come together, the volume expansion will push against the contacts opening up the gap allowing air to get deeper into the contact region. This process will repeat until a thin layer of corrosion product covers the entire contact region as shown in Figure 21. 


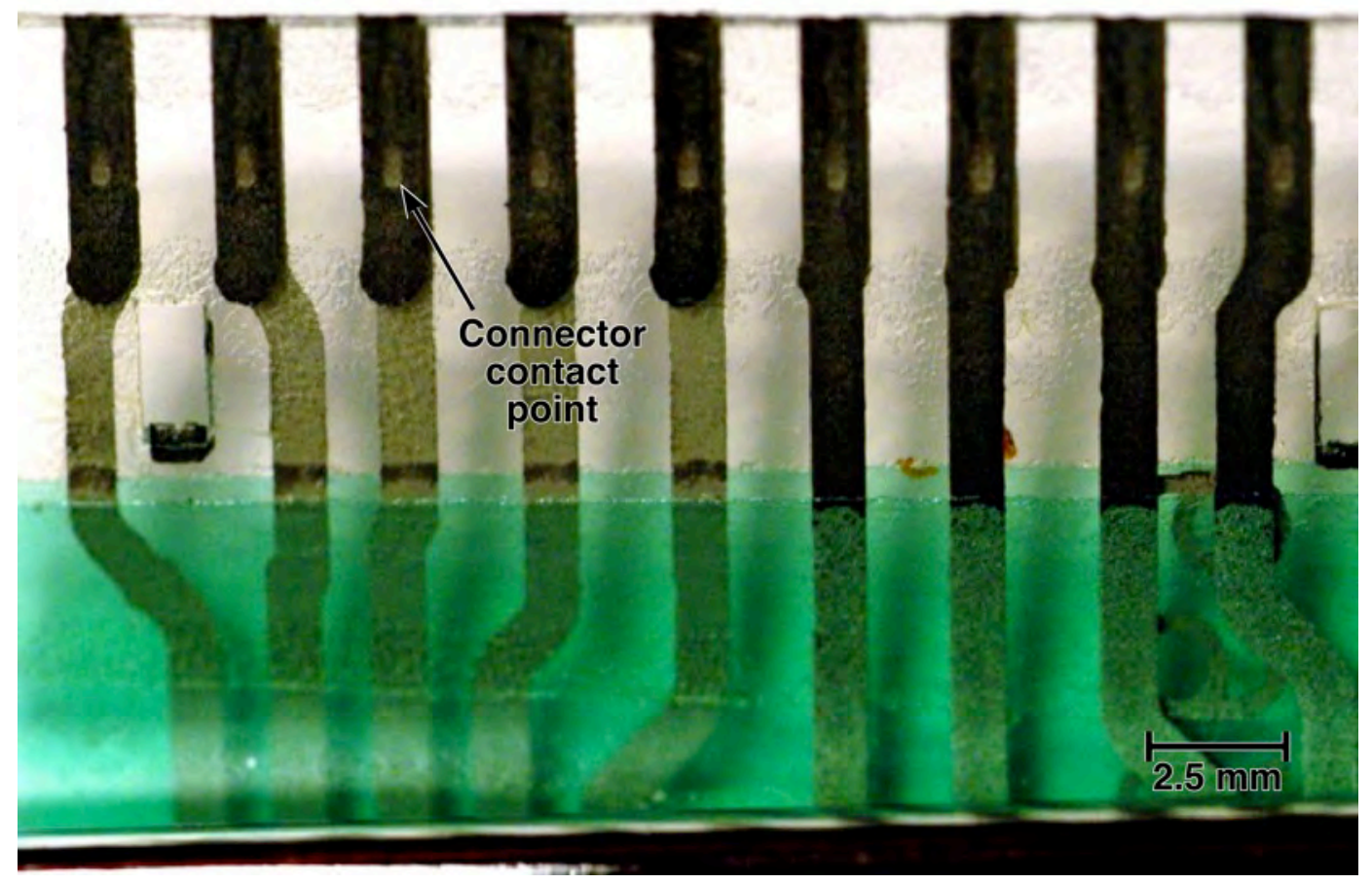

Figure 18 - Flat, flexible cable plug for low-insertion force connector.

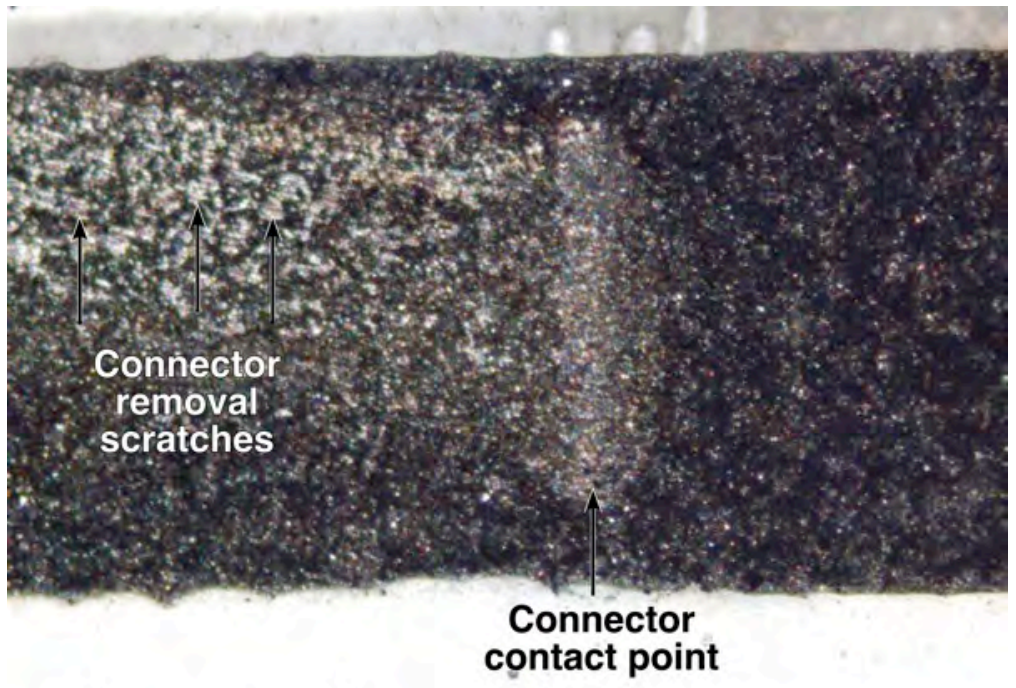

$0.5 \mathrm{~mm}$

Figure 19 - Black deposits on silver connector for flat flexible cable, connector contact area, and scratches from unplugging the cable. 


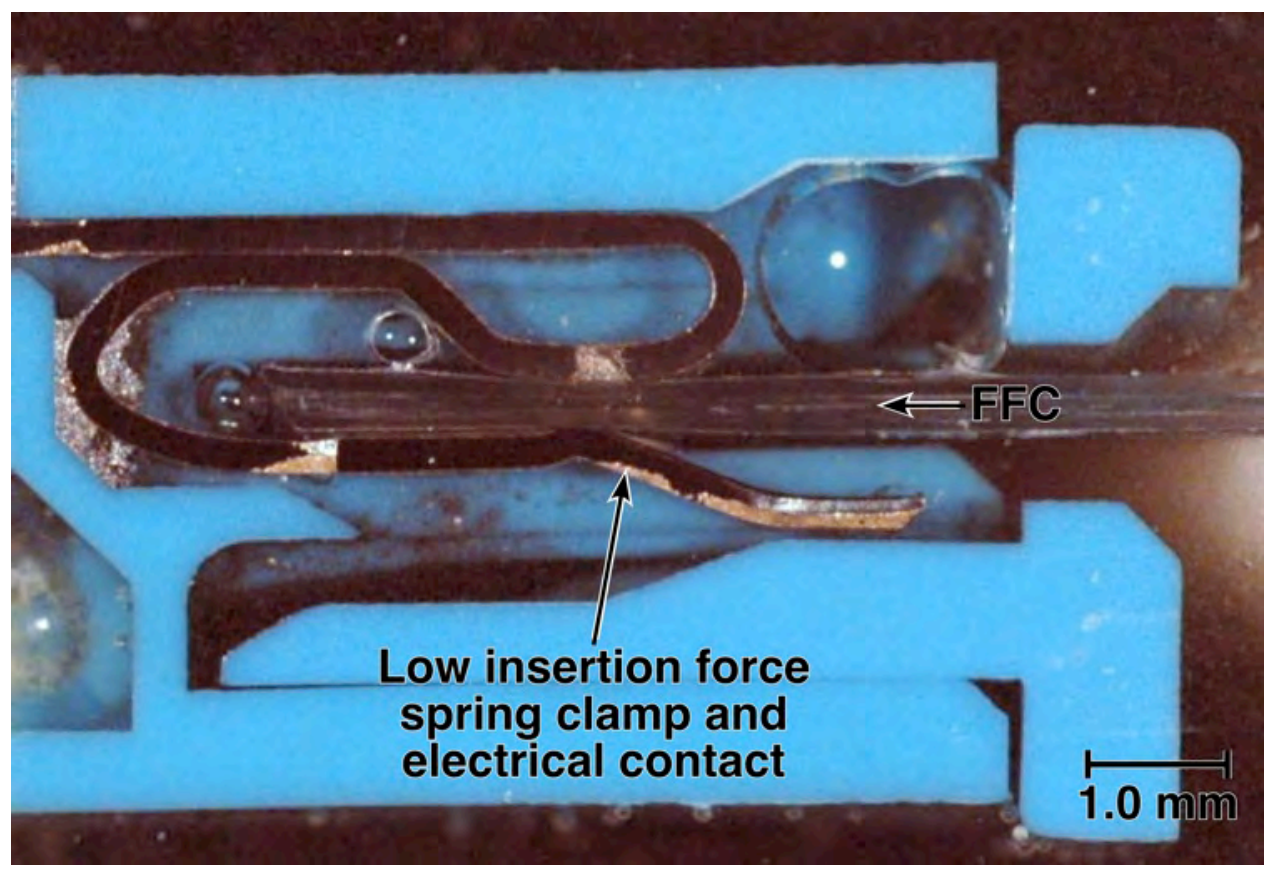

Figure 20 - Flat, flexible cable plug in low-insertion force connector mounted in clear epoxy, cross sectioned, and polished for microscopic examination.

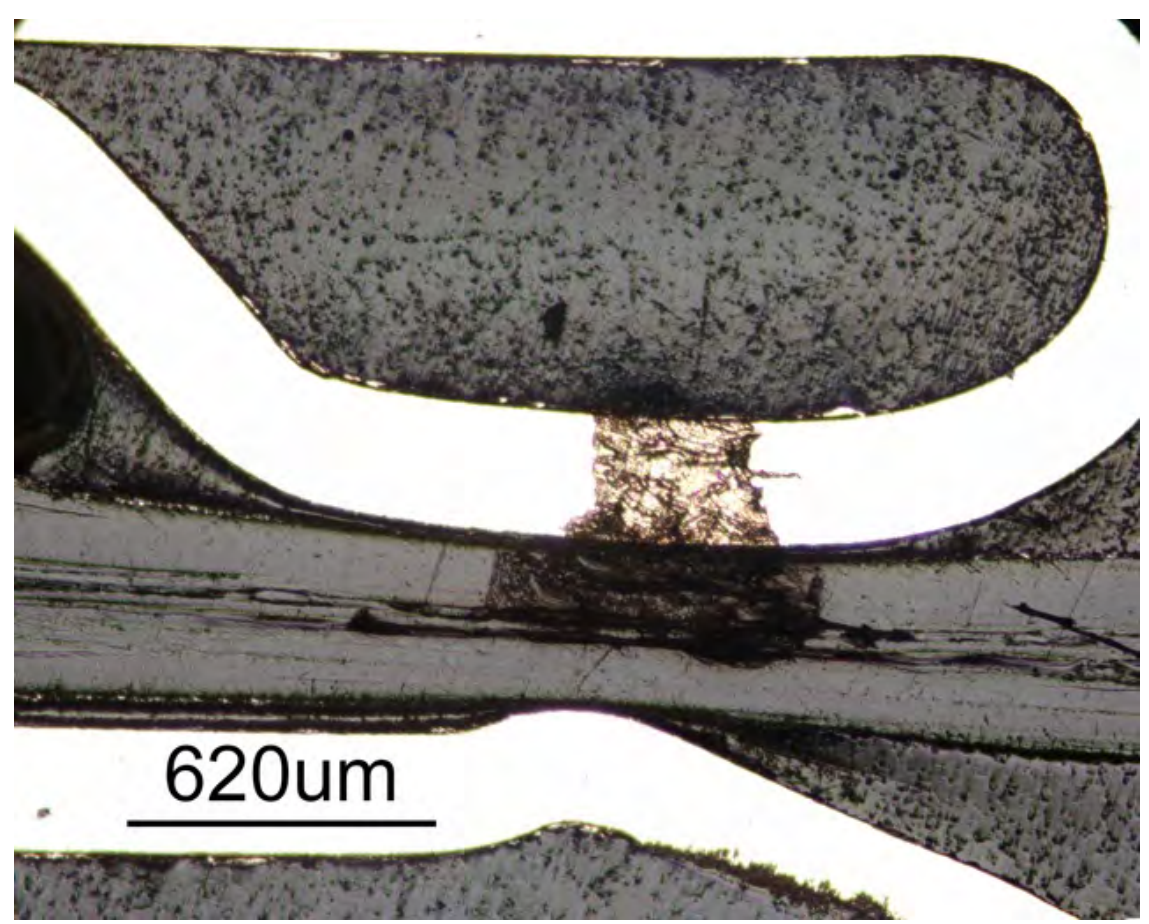

Figure 21(a) - Optical micrograph of the contact area of the flat, flexible cable plug in between the spring contacts of the female receptacle in cross section. 


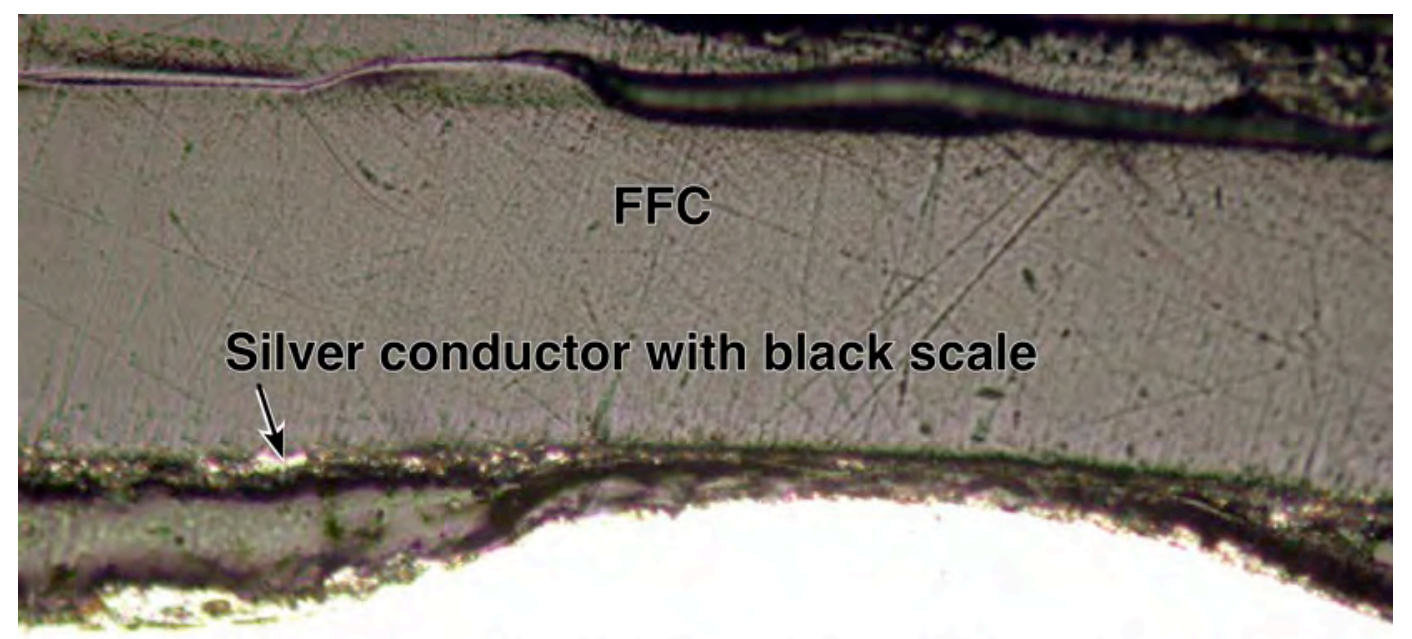

\section{Low insertion force connector spring clamp}

\section{$\stackrel{\mathrm{50 \mu \textrm {m }}}{\stackrel{1}{2}}$}

Figure 21(b) - Higher magnification view of flat, flexible cable contact area.

\section{EXAMINATION OF COMPONENTS AFTER LABORATORY EXPOSURE TESTS}

\section{A. Laboratory Exposure Testing}

Coupons of metallic alloys and samples of smoke detectors and fire sprinklers were exposed to controlled corrosive atmospheric conditions to enable estimation of the effects of long-term exposure to the problem drywall home atmosphere on these alloys and components. These exposures were conducted at the Facility for Atmospheric Corrosion Testing (FACT II) at Sandia National Laboratory (SNL). Considerable research can be required to identify environments for accurate emulation of long-term field exposures in relatively short laboratory experiments. Fortunately, Abbott ${ }^{7,8}$ investigated accelerated testing environments for emulation of the effects of low-level pollutants, including $\mathrm{H}_{2} \mathrm{~S}$, on atmospheric corrosion of electronic components. In addition, the FACT II facility at SNL is specially designed for conducting tests in mixed flowing gas environments of the type that $\mathrm{Abbott}^{7,8}$ found to produce the best emulation of field exposures of this type. Based upon the results of the indoor air quality study of residences with problem drywall, ${ }^{9}$ the environments in these homes were classified as Class IV corrosive environments ${ }^{8}$; the testing environment selected to represent this environment in accelerated testing is given in Table I. One week in this environment is believed to be equivalent to roughly 5 years of exposure in a Class IV environment. The metal coupons were exposed to this environment for 60 days ( 8.6 weeks). ${ }^{7,8}$ So, the corrosion damage on these samples should be 
roughly equivalent to that expected for 40 years of exposure in problem drywall homes. The uncertainty in this acceleration ratio is essentially unquantifiable because it assumes that all corrosion modes, kinetic factors, and incubation times are accelerated uniformly for all alloys, sample geometries, and components; and there is not 40 years of data for evaluation of these assumptions. This estimate also assumes a constant $\mathrm{H}_{2} \mathrm{~S}$ level for the entire 40 years of exposure; however, because the drywall in a home has a finite volume of material, these levels will almost certainly decline over time. Accelerated corrosion tests of this type have been used successfully throughout industry and government for critical decision-making for nearly a century. In addition, the best state-of-the-art techniques and research were used in the design of these tests and the selection of the testing environment. ${ }^{7,8,10}$

\section{TABLE I}

The mixed flowing gas environment used to represent Class IV atmospheric corrosion environments in accelerated exposure tests at the FACT II facility at Sandia National Laboratories. These values represent the controlled input quantities of the gases. The gasses were supplied using permeation tubes and mass flow controllers. The chamber volume was 300 $\mathrm{L}$; the total flow rate was $12 \mathrm{~L} / \mathrm{m}$; the temperature $50{ }^{\circ} \mathrm{C}$; and the pressure in the chamber was $101 \mathrm{kPa}$.

\begin{tabular}{|c|c|}
\hline Gas & Volume per L in Air \\
\hline $\mathrm{H}_{2} \mathrm{~S}$ & $200 \mathrm{~nL}$ \\
\hline $\mathrm{NO}_{2}$ & $200 \mathrm{~nL}$ \\
\hline $\mathrm{Cl}_{2}$ & $50 \mathrm{~nL}$ \\
\hline $\mathrm{H}_{2} \mathrm{O}$ & $75 \%$ Relative Humidity \\
\hline
\end{tabular}

\section{B. Corrosion Coupons}

(1) Sample Design and Alloy Selection. There were two objectives in exposing metals and alloys to the accelerated test environment: (i) to enable estimation of failure times of life safety critical components, and (ii) to evaluate the potential for localized forms of attack, such as stress corrosion cracking, pitting, and crevice corrosion, which is especially hazardous for gas service piping components. These were identified as the objectives of these experiments in a meeting between staff from CPSC, SNL, and NIST. Because these were the objectives - and not functional tests of components - representative coupons, and not actual components, were used for these exposures. This decision was influenced by the measurements of corrosion product film thickness presented above in Section II.F (also Figure 9), where it was determined that functional failure of tubing or fittings should not occur in these tests, and simple pass/fail tests would not produce any additional data. Therefore, it was decided to use flat, rectangular coupons that would produce the most accurate corrosion rate measurements. Stressed U-bend coupons of stainless steel and welded stainless steel were included to enable evaluation of the possibility of localized or stress-related corrosion attack. The geometry of both types of coupons followed ASTM guidelines, ${ }^{11,12}$ as shown in Figure 22. The samples were prepared, cleaned, and analyzed following ASTM procedures. ${ }^{11-14}$ 


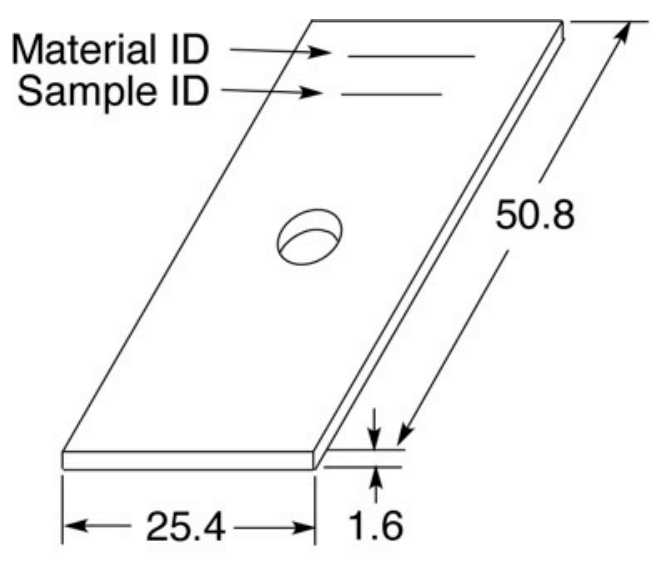

(a) Flat coupons

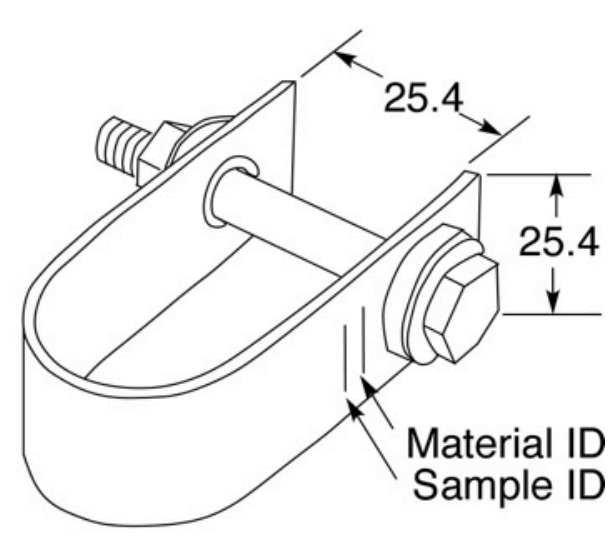

(b) U-bend coupons

Figure 22 - Corrosion coupons designs selected for the accelerated corrosion tests.

Four alloys were selected for the flat corrosion rate coupons: (1) commercial purity copper (CDA 122), (2) Brass (CDA 360), (3) commercial purity silver, and (4) AISI 304 Stainless Steel. Four types of U-bend coupons were also used: (1) commercial purity copper (CDA 122), (2) brass (CDA 360), (3) AISI 304 stainless steel, and (4) welded AISI 304 stainless steel (with the weld at the apex of the bend). The stainless steel alloy was selected to represent corrugated flex tubing. The copper and brass alloys were selected to represent copper fuel gas tubing and brass fittings. Silver was included in this matrix, due to the observation of the failure in the FFC connector in the microwave oven. Silver was not included in the U-bends because it is not used under stress, and the welded 304 U-bend coupons were included to insure coverage of the special metallurgical variations in the heat-affected zones in stainless steels. Black iron and carbon steel were not included in the matrix because the home inspections did not indicate any serious acceleration of corrosion in these alloys. Five samples of each type and alloy, for a total of 40 samples, were exposed in the FACT II chamber at SNL for $60 \mathrm{~d}$. This exposure is expected to produce the corrosion damage anticipated after $40 \mathrm{y}$ in service.

A commercial vendor, with experience in the fabrication of corrosion coupons that meet ASTM specifications, fabricated the samples. The samples were stamped with the alloy and sequentially numbered. The samples were then shipped to NIST, where they were weighed and shipped to SNL. At SNL, the samples were cleaned with a dilute hydrochloric acid solution $(10 \%)$ to remove any corrosion inhibitors adsorbed during shipping and reweighed. The samples were then exposed for $60 \mathrm{~d}$ to the Class IV accelerated corrosion environment in the FACT II facility at Sandia and reweighed. The samples were then shipped to NIST, where they were weighed again and examined.

(2) Optical Examination Results. Figure 23 shows photographs of the five flat coupon samples of each alloy after exposure to the accelerated test environment at SNL. Figure 24 shows a photograph of a representative sample of each alloy, after exposure, next to a sample that was not exposed to the accelerated test environment. By comparing these photographs, it can be seen that the alloys that contain copper formed very dark deposits that appear to be thick due to the dark opaque color of these deposits. The silver samples are also significantly altered 
by this exposure, although the change seems to be more of a case of loss of luster rather than the development of a corrosion product. No evidence of general or localized attack was observed on any of the stainless steel coupons. Similar deposits were found on the U-bend coupons, but no evidence of any form of localized corrosion, pitting, or stress corrosion cracking was found on any of the samples.

(a) Copper (CDA 122)
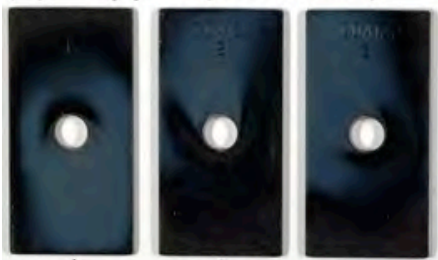

(b) Brass (CDA 360)
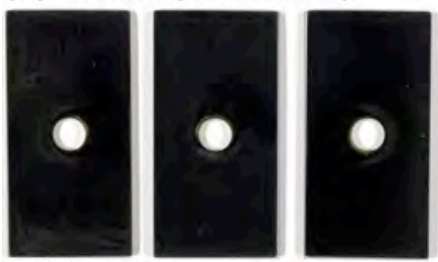
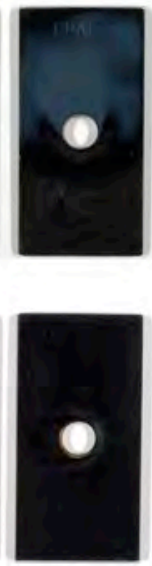

(c) Stainless Steel (AISI 304)
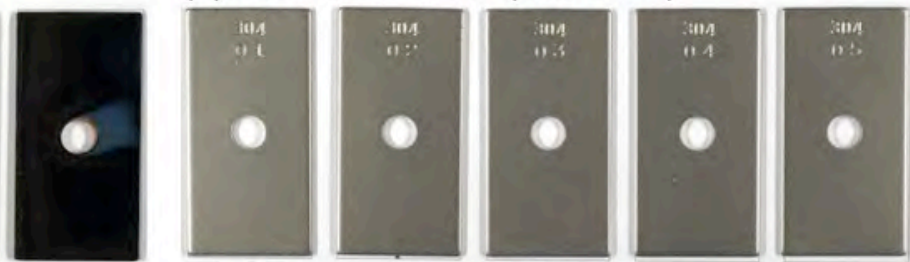

(d) Silver
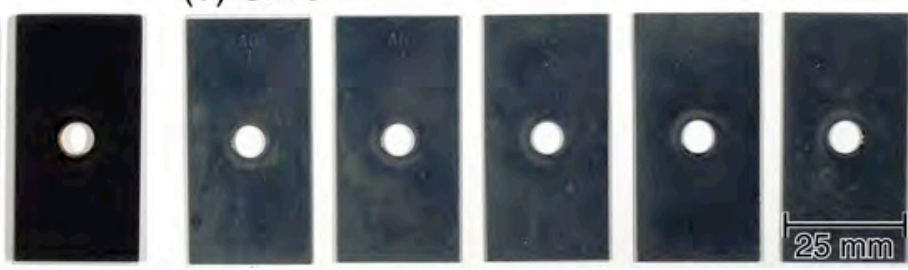

Figure 23 - Flat coupons after exposure to the simulated Class IV accelerated corrosion environment at SNL.

(a) Copper (CDA 122)

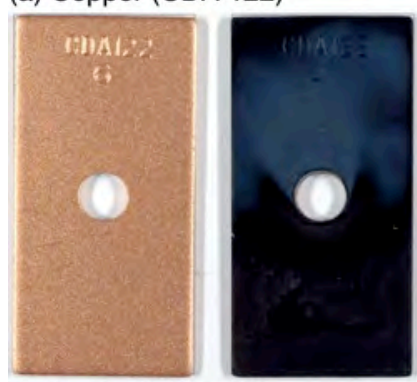

(b) Brass (CDA 360)

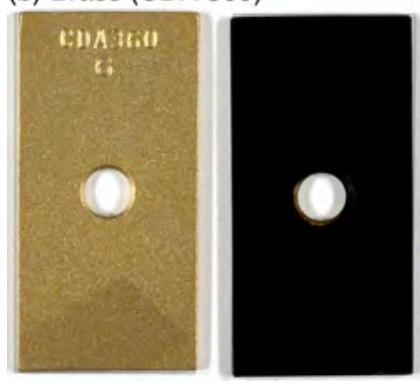

(c) Stainless Steel (AISI 304)
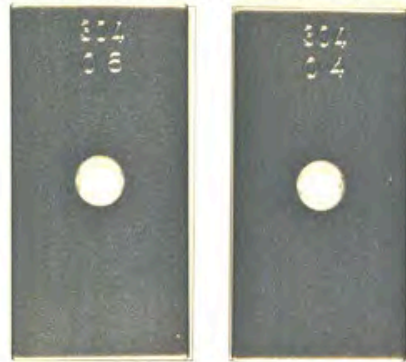

(d) Silver


Figure 24 - Unexposed samples (left side) compared to samples of the same alloy after 60 days of exposure to the accelerated testing environment at SNL (right side). The unexposed silver sample appears dark because its mirror-like surface is highly reflective. 
(3) X-ray Diffraction Results. The corrosion product scales on the accelerated test coupons were analyzed by X-ray diffraction for comparison to the scales found on samples removed from homes with problem drywall. This also enabled the use of corrosion product stoichiometry in the analysis of the coupon mass change measurements. A commercial diffractometer with a $\mathrm{Cu} \mathrm{K}$ alpha radiation source and a gas-filled $2 \mathrm{D}$ area detector at a $15 \mathrm{~cm}$ sample-to-detector distance with a field of view of 35 degrees was used. The X-ray beam spot size was $0.5 \mathrm{~mm} \times 1.5 \mathrm{~mm}$ in lateral dimensions. Three consecutive scans were performed over the 2-theta range from 20 degrees to 100 degrees. Table II shows the results of this analysis, and Figure 25 shows powder diffraction scans, one each obtained from a sample of copper (CDA122), brass (CDA360) and silver. It should be noted that the X-ray diffraction results show that the accelerated testing environment with its greater concentrations of reactants, including $\mathrm{H}_{2} \mathrm{~S}$, altered the corrosion product on the surface of copper and brass from the digenite phase $\left(\mathrm{Cu}_{9} \mathrm{~S}_{5}\right)$ found on samples removed from homes with problem wallboard to the covelite phase (CuS). The deposit on the silver sample was found by X-ray diffraction to be acanthite $\left(\mathrm{Ag}_{2} \mathrm{~S}\right)$. A similar analysis was not performed on samples from problem drywall homes, but silver has only one sulfide phase that is stable at ambient temperatures.
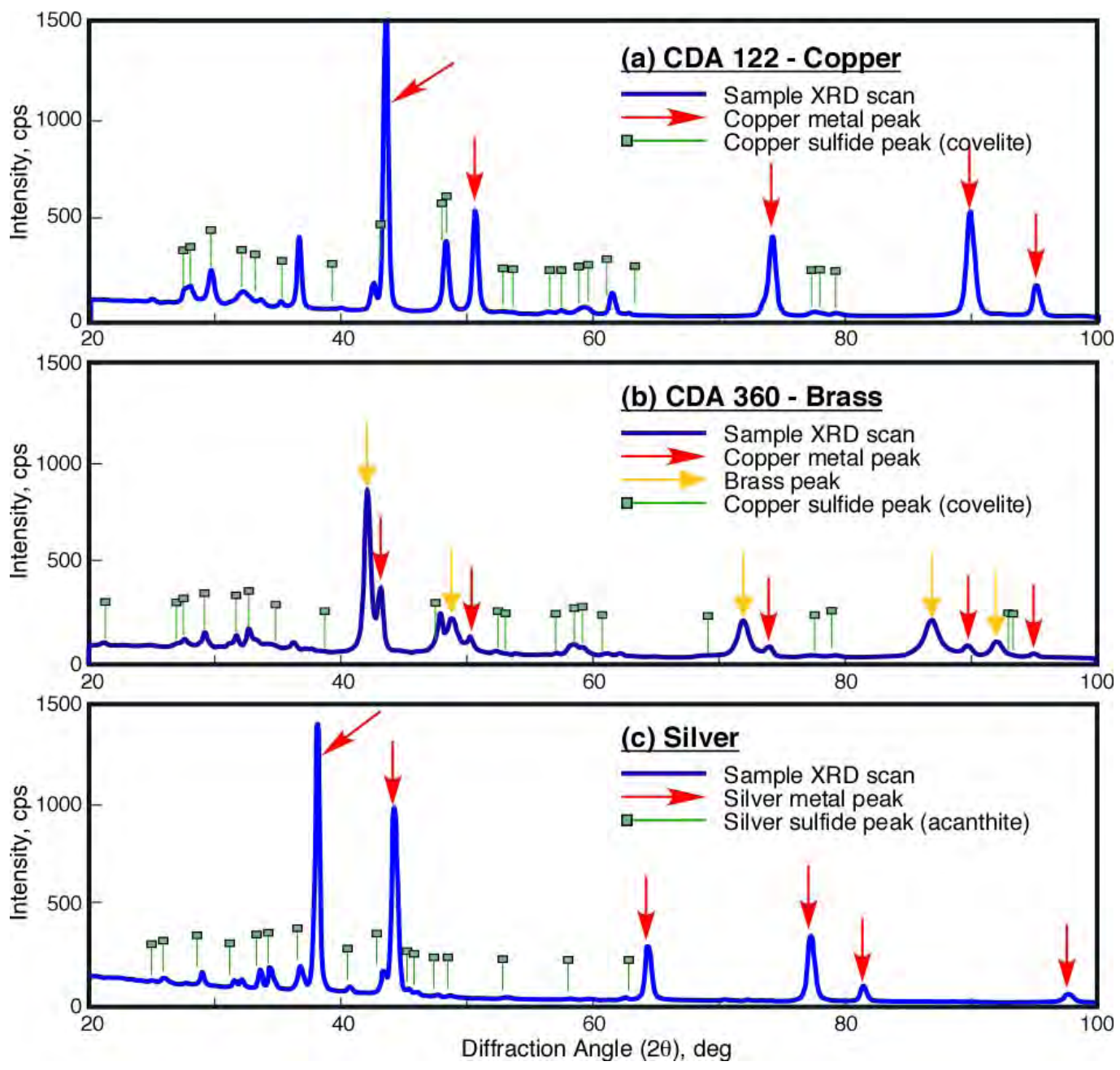

Figure 25 - X-ray powder diffraction scans from samples of three alloys after exposure to the accelerated testing atmosphere for 60 days. Table II summarizes the findings. 
(4) Mass Change Measurement Results. Table III shows the mass of the flat coupon samples measured at NIST and SNL in Tables III(a) and III(b), respectively, with the standard deviations calculated for multiple measurements. Three of the flat coupons of each alloy were descaled following ASTM procedures (ASTM G01-03 ${ }^{13}$ ) and then weighed (5 repeat measurements) after removal of the scale. The results of these measurements are provided in Table III(c). The remaining two coupons were used for X-ray diffraction and metallographic sectioning. In the case of calculated quantities, the uncertainty (Unc.) is an estimate of the expected standard deviation calculated from the standard deviations in the measured quantities.

\section{TABLE II}

Phases identified in the X-ray powder diffraction patterns from the corrosion coupons by matching peaks to known patterns in the Inorganic Crystal Structure Database (ICSD).

\begin{tabular}{|l|l|l|l|}
\hline Coupon material & $\mathrm{Ag}$ & CDA 122 & CDA 360 \\
\hline Base metal & $\begin{array}{l}4-783, \mathrm{Ag}(\mathrm{FCC} \\
\text { metal) }\end{array}$ & $\begin{array}{l}4-836, \mathrm{Cu} \text { (FCC } \\
\text { metal) }\end{array}$ & $\begin{array}{l}4-836, \mathrm{Cu} \text { (FCC } \\
\text { metal) }\end{array}$ \\
\hline Oxide & None found & $\begin{array}{l}77-199, \mathrm{Cu}_{2} \mathrm{O} \\
\text { (Cuprite) }\end{array}$ & None found \\
\hline Chloride & None found & None found & None found \\
\hline Sulfide & $\begin{array}{l}14-072, \mathrm{Ag}_{2} \mathrm{~S} \\
\text { (Acanthite) }\end{array}$ & $\begin{array}{l}6-464, \mathrm{CuS} \\
\text { (Covellite) }\end{array}$ & $\begin{array}{l}\text { 6-464, CuS } \\
\text { (Covellite) }\end{array}$ \\
\hline Other & --- & --- & $\begin{array}{l}50-1333, \text { Cu-Zn } \\
\text { (alpha-brass) }\end{array}$ \\
\hline
\end{tabular}

TABLE III(a)

Mass change measurements for the flat corrosion rate coupons, as determined from 5 repeat measurements performed at NIST.

\begin{tabular}{|c|c|c|c|c|c|c|c|c|}
\hline \multirow{2}{*}{ Alloy } & \multirow{2}{*}{$\begin{array}{l}\text { Sample } \\
\quad \#\end{array}$} & \multicolumn{2}{|c|}{$\begin{array}{l}\text { NIST Before Shipping to } \\
\text { SNL }\end{array}$} & \multicolumn{2}{|c|}{$\begin{array}{l}\text { NIST After receipt from } \\
\text { SNL }\end{array}$} & \multicolumn{3}{|c|}{ Mass Change } \\
\hline & & Mean, $g$ & Std Dev, g & Mean, g & Std Dev, g & $\Delta \mathrm{M}, \mathrm{g}$ & Mean, $\mathrm{g}$ & Std Dev, g \\
\hline \multirow{5}{*}{ CDA122 } & 1 & 17.85110 & 0.000010 & 17.87266 & 0.000011 & 0.02156 & \multirow{5}{*}{0.02312} & \multirow{5}{*}{0.00127} \\
\hline & 2 & 17.84835 & 0.000010 & 17.87130 & 0.000007 & 0.02295 & & \\
\hline & 3 & 17.85590 & 0.000018 & 17.87946 & 0.000026 & 0.02355 & & \\
\hline & 4 & 17.85484 & 0.000005 & 17.87738 & 0.000006 & 0.02254 & & \\
\hline & 5 & 17.79816 & 0.000006 & 17.82314 & 0.000005 & 0.02498 & & \\
\hline \multirow{5}{*}{ CDA360 } & 1 & 19.24950 & 0.000013 & 19.27859 & 0.000016 & 0.02908 & \multirow{5}{*}{0.02858} & \multirow{5}{*}{0.00047} \\
\hline & 2 & 19.19115 & 0.000024 & 19.21900 & 0.000017 & 0.02785 & & \\
\hline & 3 & 18.93715 & 0.000021 & 18.96579 & 0.000007 & 0.02865 & & \\
\hline & 4 & 19.45920 & 0.000010 & 19.48765 & 0.000020 & 0.02845 & & \\
\hline & 5 & 19.29652 & 0.000009 & 19.32539 & 0.000012 & 0.02887 & & \\
\hline \multirow{5}{*}{$\mathrm{Ag}$} & 1 & 8.70521 & 0.000005 & 8.70591 & 0.000013 & 0.00070 & \multirow{5}{*}{0.00073} & \multirow{5}{*}{0.00017} \\
\hline & 2 & 8.65373 & 0.000007 & 8.65418 & 0.000010 & 0.00045 & & \\
\hline & 3 & 8.68679 & 0.000007 & 8.68769 & 0.000020 & 0.00090 & & \\
\hline & 4 & 8.85010 & 0.000006 & 8.85090 & 0.000007 & 0.00080 & & \\
\hline & 5 & 8.80671 & 0.000013 & 8.80753 & 0.000007 & 0.00082 & & \\
\hline
\end{tabular}




\begin{tabular}{|c|c|c|c|c|c|c|c|c|}
\hline \multirow{5}{*}{ AISI304 } & 1 & 14.32531 & 0.000013 & 14.32544 & 0.000005 & 0.00012 & \multirow{5}{*}{0.00012} & \multirow{5}{*}{0.00004} \\
\hline & 2 & 14.39346 & 0.000006 & 14.39362 & 0.000008 & 0.00016 & & \\
\hline & 3 & 14.36511 & 0.000011 & 14.36520 & 0.000018 & 0.00009 & & \\
\hline & 4 & 14.34643 & 0.000007 & 14.34650 & 0.000025 & 0.00007 & & \\
\hline & 5 & 14.39947 & 0.000004 & 14.39963 & 0.000020 & 0.00016 & & \\
\hline
\end{tabular}

TABLE III(b)

Mass change measurements for the flat corrosion rate coupons, as determined from measurements conducted at SNL. Because the samples were pickled in $\mathrm{HCl}$ at SNL to remove surface films that may have been adsorbed during shipping, these masses should differ from those determined from the mass measurements conducted at NIST.

\begin{tabular}{|c|c|c|c|c|c|c|c|c|}
\hline \multirow[b]{2}{*}{ Alloy } & \multirow{2}{*}{$\begin{array}{c}\text { Sample } \\
\#\end{array}$} & \multicolumn{2}{|c|}{ SNL after Pickling } & \multicolumn{2}{|c|}{ SNL after Exposure } & \multicolumn{3}{|c|}{ Mass Change } \\
\hline & & $\begin{array}{l}\text { Mean, g } \\
\text { (3 Meas) }\end{array}$ & Std Dev, g & $\begin{array}{l}\text { Mass, } g \\
\text { (1 Meas) }\end{array}$ & Std Dev, g & $\Delta \mathrm{M}, \mathrm{g}$ & Mean, g & Std Dev, $g$ \\
\hline \multirow{5}{*}{ CDA122 } & 1 & 17.85073 & 0.000002 & 17.87308 & - & 0.02234 & \multirow{5}{*}{0.02400} & \multirow{5}{*}{0.00118} \\
\hline & 2 & 17.84801 & 0.000002 & 17.87180 & - & 0.02380 & & \\
\hline & 3 & 17.85571 & 0.000001 & 17.88021 & - & 0.02449 & & \\
\hline & 4 & 17.85449 & 0.000002 & 17.87828 & - & 0.02379 & & \\
\hline & 5 & 17.79774 & 0.000002 & 17.82333 & - & 0.02559 & & \\
\hline \multirow{5}{*}{ CDA360 } & 1 & 19.24840 & 0.000002 & 19.27833 & - & 0.02993 & \multirow{5}{*}{0.02932} & \multirow{5}{*}{0.00038} \\
\hline & 2 & 19.18970 & 0.000001 & 19.21864 & - & 0.02894 & & \\
\hline & 3 & 18.93654 & 0.000002 & 18.96562 & - & 0.02909 & & \\
\hline & 4 & 19.45843 & 0.000001 & 19.48765 & - & 0.02922 & & \\
\hline & 5 & 19.29593 & 0.000001 & 19.32533 & - & 0.02940 & & \\
\hline \multirow{5}{*}{$\mathrm{Ag}$} & 1 & 14.32616 & 0.000001 & 14.32626 & - & 0.00011 & \multirow{5}{*}{0.00011} & \multirow{5}{*}{0.00002} \\
\hline & 2 & 14.39440 & 0.000003 & 14.39452 & - & 0.00012 & & \\
\hline & 3 & 14.36604 & 0.000001 & 14.36618 & - & 0.00014 & & \\
\hline & 4 & 14.34731 & 0.000002 & 14.34742 & - & 0.00011 & & \\
\hline & 5 & 14.40038 & 0.000002 & 14.40046 & - & 0.00009 & & \\
\hline \multirow{5}{*}{ AISI304 } & 1 & 8.70569 & 0.000002 & 8.70738 & - & 0.00169 & \multirow{5}{*}{0.00166} & \multirow{5}{*}{0.00007} \\
\hline & 2 & 8.65417 & 0.000001 & 8.65578 & - & 0.00160 & & \\
\hline & 3 & 8.68725 & 0.000001 & 8.68885 & - & 0.00160 & & \\
\hline & 4 & 8.85060 & 0.000002 & 8.85223 & - & 0.00164 & & \\
\hline & 5 & 8.80721 & 0.000001 & 8.80898 & - & 0.00177 & & \\
\hline
\end{tabular}

TABLE III(c)

Mass change measurements for the flat corrosion rate coupons when descaled at NIST in a deaerated $\mathrm{HCl}$ solution.

\begin{tabular}{|c|c|c|c|c|c|c|c|c|c|}
\hline \multirow[b]{2}{*}{ Alloy } & \multirow[b]{2}{*}{$\begin{array}{l}\text { Sample } \\
\#\end{array}$} & \multicolumn{2}{|c|}{ Before Descalling } & \multicolumn{2}{|c|}{ After Descaling } & \multirow{2}{*}{$\begin{array}{c}\begin{array}{c}\text { Mass } \\
\text { Chg. }\end{array} \\
\Delta \mathrm{M} \\
(\mathrm{NIST}) \mathrm{g}\end{array}$} & \multicolumn{3}{|c|}{ Scale Mass Estimates } \\
\hline & & Mean, g & $\begin{array}{l}\text { Std Dev, } \\
\quad \mathrm{g}\end{array}$ & Mean, $\mathrm{g}$ & $\begin{array}{l}\text { Std Dev, } \\
\quad \mathrm{g}\end{array}$ & & $\begin{array}{l}\text { Est } \\
\text { Scale } \\
\text { Mass }\end{array}$ & Mean & $\begin{array}{c}\text { Std Dev, } \\
\text { g }\end{array}$ \\
\hline CDA122 & 1 & 17.87266 & 0.000011 & 17.78143 & 0.000005 & 0.09123 & 0.08257 & \multirow{3}{*}{0.08739} & \multirow{3}{*}{0.000038} \\
\hline CDA122 & 2 & 17.87131 & 0.000005 & 17.77272 & 0.000000 & 0.09859 & 0.08992 & & \\
\hline CDA122 & 3 & 17.87947 & 0.000019 & 17.78112 & 0.000009 & 0.09835 & 0.08968 & & \\
\hline
\end{tabular}




\begin{tabular}{|c|c|c|c|c|c|c|c|c|c|}
\hline CDA360 & 1 & 19.27858 & 0.000007 & 19.18383 & 0.000015 & 0.09475 & 0.08608 & \multirow{3}{*}{0.08295} & \multirow{3}{*}{0.000038} \\
\hline CDA360 & 2 & 19.21899 & 0.000013 & 19.12886 & 0.000010 & 0.09013 & 0.08146 & & \\
\hline CDA360 & 3 & 18.96579 & 0.000008 & 18.87582 & 0.000004 & 0.08997 & 0.08130 & & \\
\hline $\mathrm{Ag}$ & 1 & 8.70591 & 0.000012 & 8.69492 & 0.000007 & 0.01099 & 0.00233 & \multirow{3}{*}{0.00271} & \multirow{3}{*}{0.000042} \\
\hline $\mathrm{Ag}$ & 2 & 8.65418 & 0.000004 & 8.64250 & 0.000004 & 0.01168 & 0.00302 & & \\
\hline $\mathrm{Ag}$ & 3 & 8.68769 & 0.000025 & 8.67625 & 0.000009 & 0.01144 & 0.00278 & & \\
\hline CDA122 & \multirow{3}{*}{$\begin{array}{c}\text { control } \\
\text { samples }\end{array}$} & 17.85760 & 0.000012 & 17.84893 & 0.000012 & 0.00867 & - & - & - \\
\hline CDA360 & & 18.44150 & 0.000008 & 18.43598 & 0.000008 & 0.00552 & - & - & - \\
\hline $\mathrm{Ag}$ & & 8.79930 & 0.000016 & 8.79736 & 0.000016 & 0.00194 & - & - & - \\
\hline
\end{tabular}

TABLE IV(a)

Analysis of the mass change measurements based on the mass measurements at NIST.

\begin{tabular}{|c|c|c|c|c|c|c|c|c|c|}
\hline \multirow{2}{*}{ Material } & \multirow{2}{*}{ Alloy } & \multicolumn{2}{|c|}{ Mass Change $(\Delta \mathrm{M})$} & \multicolumn{2}{c|}{$\Delta \mathrm{M} /$ Unit Area } & \multicolumn{2}{c|}{$\begin{array}{c}\text { Observed Corrosion } \\
\text { Rate }(\mathrm{d}=60)\end{array}$} & \multicolumn{2}{c|}{$\begin{array}{c}\text { Estimated } \\
\text { Average } \\
\text { Penetration }\end{array}$} \\
\cline { 3 - 11 } & & Mean, g & $\begin{array}{c}\text { Std Dev, } \\
\mathrm{g}\end{array}$ & $\begin{array}{c}\text { Mean, } \\
\mathrm{g} / \mathrm{m}^{2}\end{array}$ & $\begin{array}{c}\text { Unc, } \\
\mathrm{g} / \mathrm{m}^{2}\end{array}$ & $\begin{array}{c}\text { Mean, } \\
\mathrm{g} /\left(\mathrm{m}^{2} \cdot \mathrm{d}\right)\end{array}$ & $\begin{array}{c}\text { Unc, } \\
\mathrm{g} /\left(\mathrm{m}^{2} \cdot \mathrm{d}\right)\end{array}$ & $\begin{array}{c}\text { Mean, } \\
\mu \mathrm{m}\end{array}$ & $\begin{array}{c}\text { Unc, } \\
\mu \mathrm{m}\end{array}$ \\
\hline Copper & CDA122 & 0.02312 & 0.001270 & 8.0758 & 0.4438 & 0.1346 & 0.0074 & 1.79 & 0.10 \\
\hline Brass & CDA360 & 0.02858 & 0.000474 & 9.9846 & 0.1655 & 0.1664 & 0.0028 & 2.33 & 0.01 \\
\hline Silver & $\begin{array}{c}\text { Commercial } \\
\text { Purity }\end{array}$ & 0.00073 & 0.000174 & 0.2754 & 0.0610 & 0.0046 & 0.0010 & 0.18 & 0.01 \\
\hline $\begin{array}{c}\text { Stainless } \\
\text { Steel }\end{array}$ & AISI 304 & 0.00012 & 0.000038 & 0.0421 & 0.0134 & 0.0007 & 0.0002 & NA & NA \\
\hline
\end{tabular}

TABLE IV(b)

Analysis of the mass change measurements based on the mass measurements at SNL.

\begin{tabular}{|c|c|c|c|c|c|c|c|c|c|}
\hline \multirow{2}{*}{ Material } & \multirow{2}{*}{ Alloy } & \multicolumn{2}{|c|}{ Mass Change $(\Delta \mathrm{M})$} & \multicolumn{2}{c|}{$\Delta \mathrm{M} /$ Unit Area } & \multicolumn{2}{c|}{$\begin{array}{c}\text { Observed Corrosion } \\
\text { Rate }(\mathrm{d}=60)\end{array}$} & \multicolumn{2}{c|}{$\begin{array}{c}\text { Estimated } \\
\text { Average } \\
\text { Penetration }\end{array}$} \\
\cline { 2 - 10 } & & Mean, g & $\begin{array}{c}\text { Std Dev, } \\
\mathrm{g}\end{array}$ & $\begin{array}{c}\text { Mean, } \\
\mathrm{g} / \mathrm{m}^{2}\end{array}$ & $\begin{array}{c}\text { Unc.., } \\
\mathrm{g} / \mathrm{m}^{2}\end{array}$ & $\begin{array}{c}\text { Mean, } \\
\mathrm{g} /\left(\mathrm{m}^{2} \cdot \mathrm{d}\right)\end{array}$ & $\begin{array}{c}\text { Unc, } \\
\mathrm{g} /\left(\mathrm{m}^{2} \cdot \mathrm{d}\right)\end{array}$ & $\begin{array}{c}\text { Mean, } \\
\mu \mathrm{m}\end{array}$ & $\begin{array}{c}\text { Unc, } \\
\mu \mathrm{m}\end{array}$ \\
\hline Copper & CDA122 & 0.02400 & 0.001183 & 8.4747 & 0.4537 & 0.1412 & 0.0076 & 1.85 & 0.09 \\
\hline Brass & CDA360 & 0.02932 & 0.000381 & 10.2319 & 0.2506 & 0.1705 & 0.0042 & 2.39 & 0.03 \\
\hline Silver & $\begin{array}{c}\text { Commercial } \\
\text { Purity }\end{array}$ & 0.00011 & 0.000018 & 0.0416 & 0.0068 & 0.0007 & 0.0001 & 0.03 & 0.00 \\
\hline $\begin{array}{c}\text { Stainless } \\
\text { Steel }\end{array}$ & AISI 304 & 0.00166 & 0.000071 & 0.5934 & 0.0281 & 0.0099 & 0.0005 & $\mathrm{NA}$ & $\mathrm{NA}$ \\
\hline
\end{tabular}

(5) Estimation of Mass Change Rates. If one assumes a coupon composed of a pure metal, A, reacts with an environment species, B, to form a single stoichiometric compound of the form $A_{x} B_{y}$ in manner such that all of the product formed is retained on the surface, then one can estimate the amount of A consumed in the reaction $\left(Q_{A}\right)$ and estimate the average depth of penetration $(<P>)$ from the mass increase of the coupon $(\Delta M)$ using the stoichiometric coefficients of the product phase $(x, y)$. In this case, all of the mass gain corresponds to the amount of B added to the surface to form the product and the average penetration is estimated from the density of the metal in the coupon $\left(\rho_{A}\right)$ and the surface area of the coupon $\left(S_{A}\right)$. The quantity of A consumed by this reaction is then 


$$
Q_{A}=\left(\frac{x}{y}\right) \frac{\Delta M}{W_{B}}
$$

where $W_{B}$ is the molar mass of $\mathrm{B}$ and the average depth of the penetration of corrosion into the sample is

$$
\langle P\rangle=\left(\frac{x}{y}\right) \frac{\Delta M W_{A}}{W_{B} \rho_{A} S_{A}}
$$

The results of estimating the average penetration depth in this manner are included in Table IV with the uncertainty (Unc) being an estimate of the standard deviation calculated from the standard deviations of the mass change measurements $\left(\sigma_{\Delta M}\right)$ into eq. (2) for the mass change and assuming the uncertainties in the other factors are insignificant compared to this factor.

Three coupons each of the copper alloy (CDA 122) and the free machining brass alloy (CDA 360 ) were descaled following the procedure recommended for these alloys in ASTM G01-03. ${ }^{13}$ This procedure consisted of dipping the alloys into a deaerated solution of hydrochloric acid $(\mathrm{HCl})$ until the scale was removed. Nearly all of the scale was removed immediately from the copper alloy, but the scale could not be completely removed from the brass alloy. The coupons were reweighed after this procedure, and Table $\mathrm{V}$ shows the results of these measurements.

The U-bend samples were examined to determine if there was any evidence of stress corrosion cracking, pitting, or crevice corrosion. These samples were examined by eye, macroscopically, and microscopically with a metallurgical microscope. No evidence of any of these forms of attack was found on any of these samples. Figure 26 and 27 are macro photographs of the apex of the bend section of all 20 of the U-bend samples exposed to the accelerated testing environment at SNL. Figure 26 shows the stressed face across the entire width of the bend while Figure 27 shows the edge and corner of the bend in each sample. In these figures, the thin layer of uniform corrosion product can be seen on the copper and brass samples, while there is no visual evidence of any attack on the stainless steel or the welded stainless steel samples. 
(a) Copper (CDA 122) U-Bend Coupons 1-5
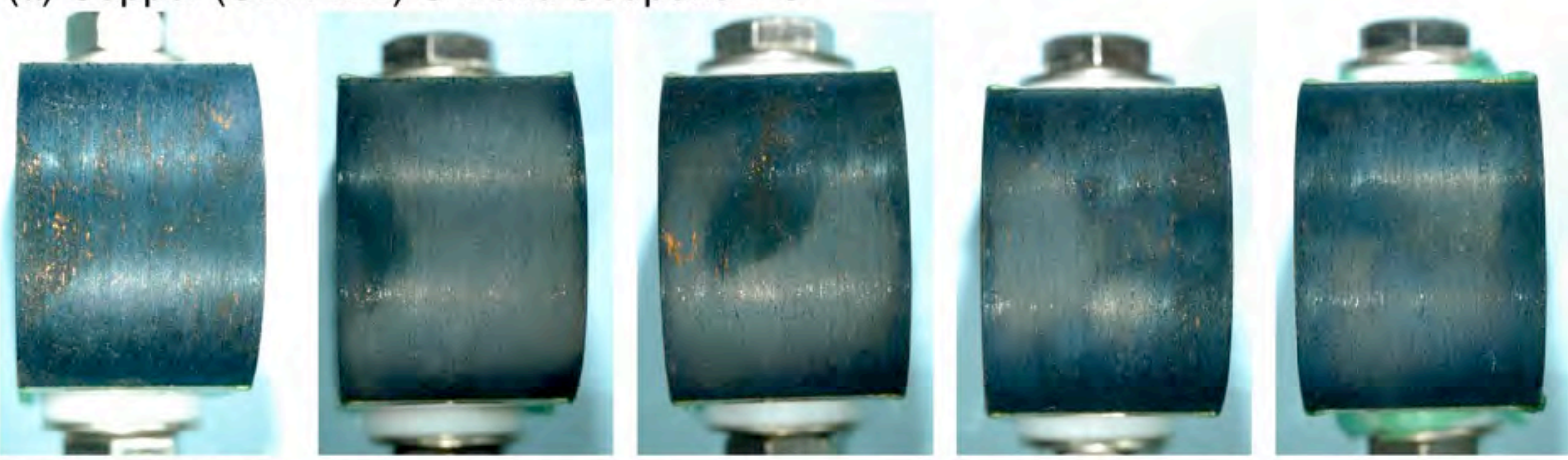

(b) Brass (CDA 360) U-Bend Coupons 1-5
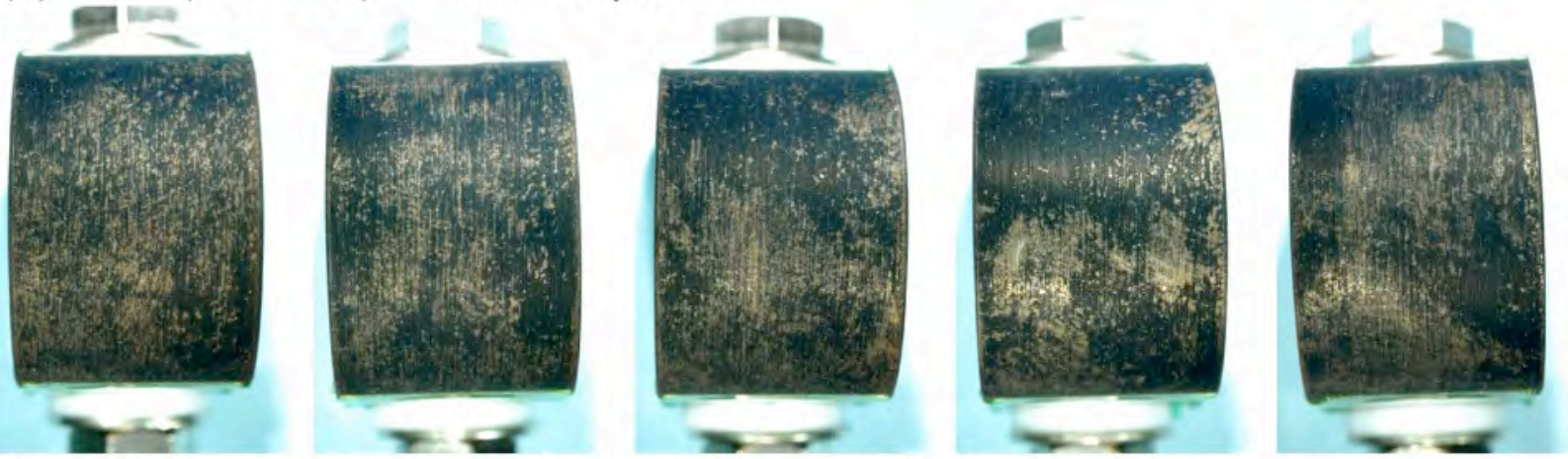

(c) Stainless Steel (AISI 304) U-Bend Coupons 1-5
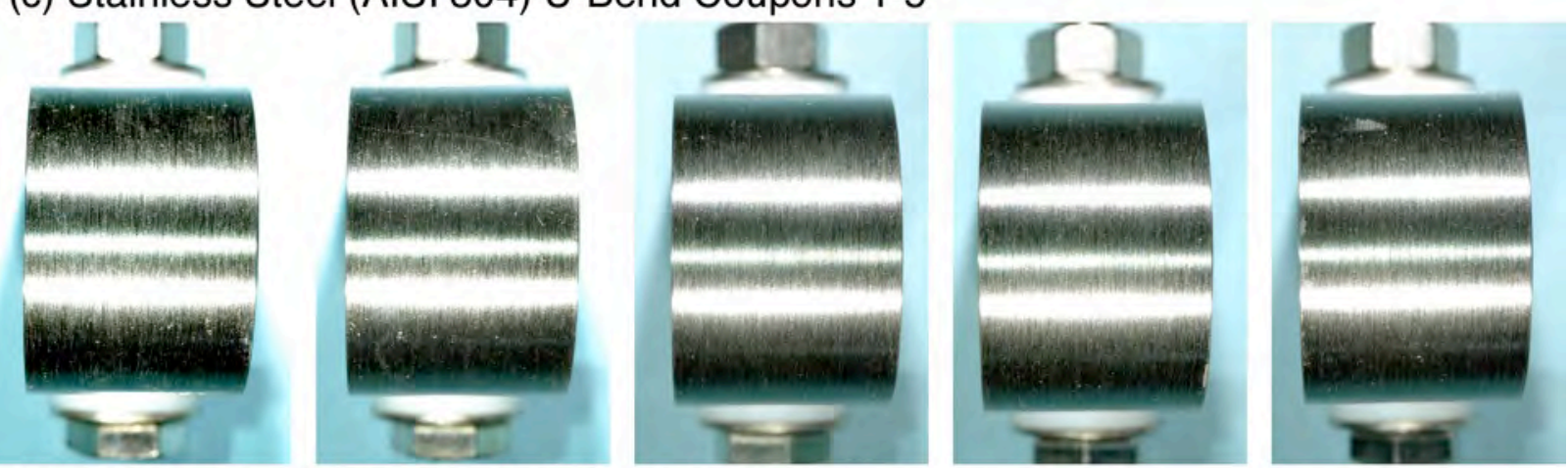

(d) Welded Stainless Steel (AISI 304) U-Bend Coupons 1-5
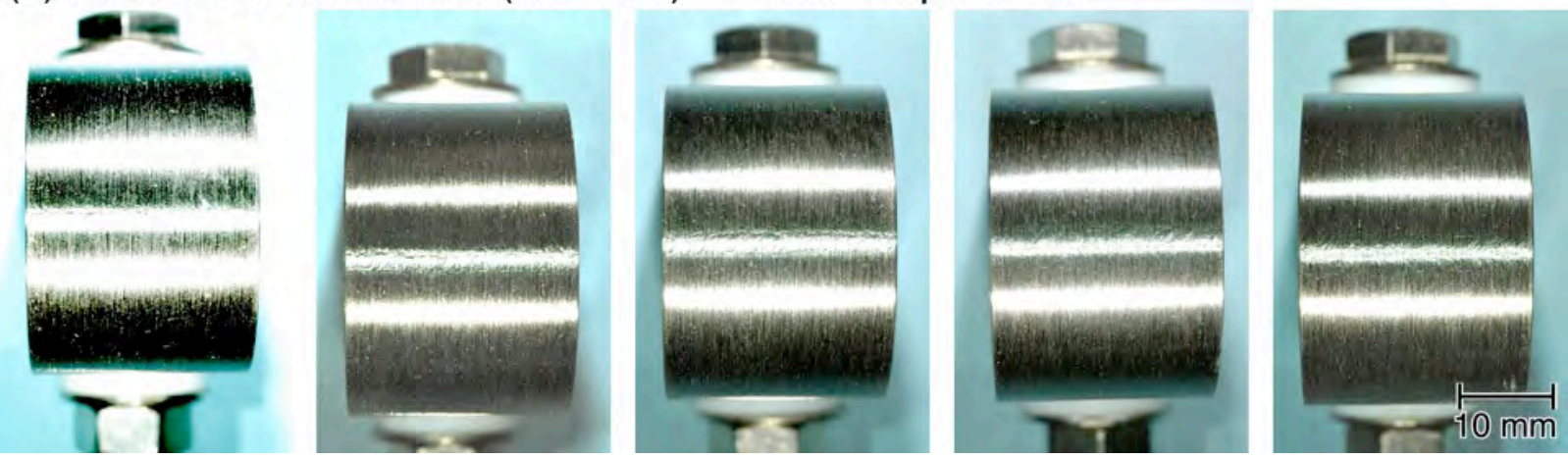

Figure 26 - Macro photographs of the bend apex in all 20 of the U-bend samples exposed to the accelerated testing environment at SNL. 
(a) Copper (CDA 122) U-bend coupons 1-5
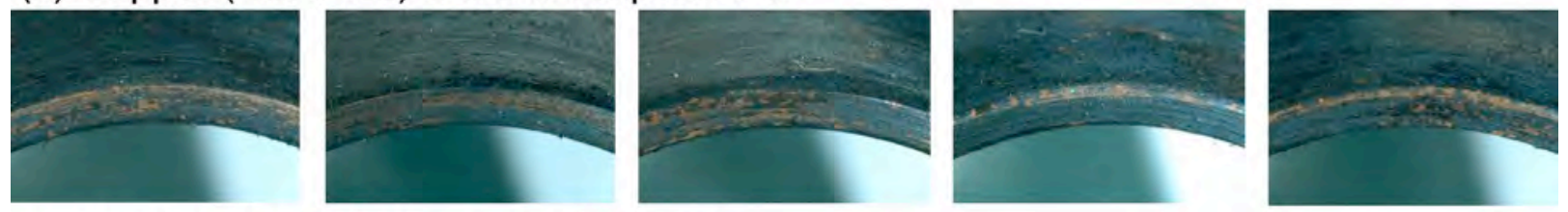

(b) Brass (CDA 360) U-bend coupons 1-5
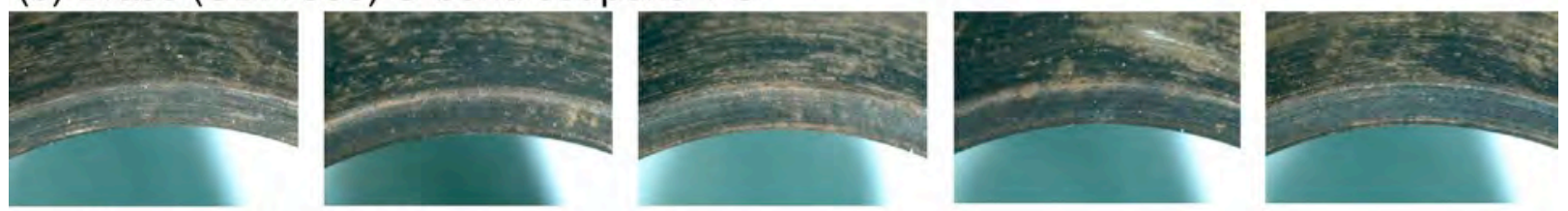

(c) Stainless Steel (AISI 304) U-bend coupons 1-5
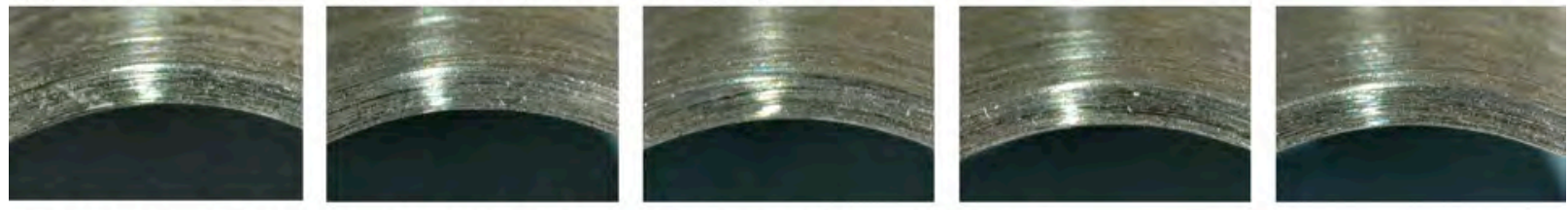

(d) Welded Stainless Steel (AISI 304) U-bend coupons 1-5
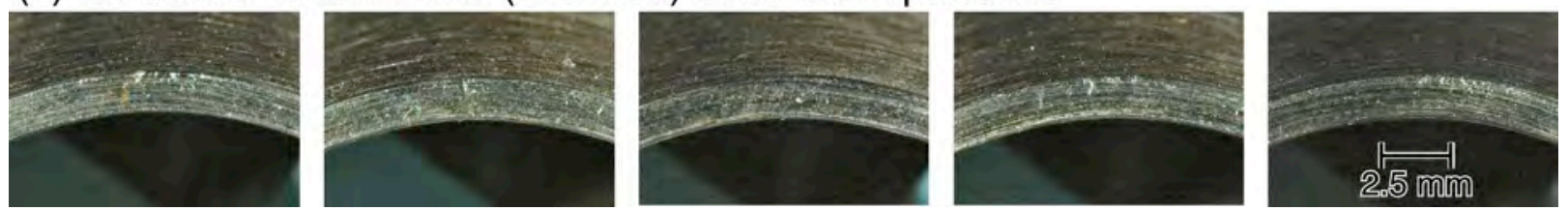

Figure 27 - The edge of all 20 of the U-bend samples tested in the accelerated testing environment at SNL

\section{Smoke Detector Alarms}

(1) Smoke Detector Alarm Exposures and Functional Tests: Thirty-six (36) smoke alarms were subjected to accelerated aging in the Class IV environment (Table I) for 2 weeks. There are two different sensor technologies used to detect smoke in these alarms (photoelectric and ionization), and three designs of each type were exposed to the accelerated corrosion environment at the FACT II facility at SNL for 2 weeks. Research indicates that this exposure is approximately equivalent to 10 years of exposure in a light industrial environment containing some of the pollutants of the type found in homes with problem drywall. ${ }^{7,8}$ Functional tests were conducted in the NIST Fire Safety Research Division and are reported separately. ${ }^{15}$ In these tests, 9 smoke alarms exhibited differences in functionality, but only one failed to trigger an alarm when exposed to smoke. Five smoke alarm samples exhibited a weak or discontinuous alarm, four smoke alarms samples failed to signal alarm to the interconnect connection, and two samples lost connection to the AC power but functioned normally with power from the battery. All of the smoke alarm units that did not function normally were ionization-type alarms that use radioactive Americium as a source of ionizing radiation. One of the smoke detector alarms that failed to function was examined by NIST Metallurgy Division staff in the laboratory. 
(2) Results of Metallurgical Examinations: The smoke alarm examined was one that failed to produce a strong and steady alarm. Figure 28 is a photograph of this unit with the cover removed. In this figure, the circuit board, with the cell containing the electrodes and the Americium source and connections for the 9-volt battery are immediately obvious. Less obvious are the connections to the piezoelectric bending disc used for the alarm-sounding device. These connections are of the lever spring-type, and they are located on the upper left side of the circuit board in the figure. The piezoelectric alarm-sounding device is attached to the cover and makes electrical contact with these connections by pressing against them when the cover is put into place. Figure 29 is a photograph of two piezoelectric bending discs used for the alarm-sounding device in smoke alarms. The one on the left is from the alarm that failed to present a normal signal when it triggered the alarm, and the one on the right is from an alarm of the same type that had been used for smoke testing, but had not been exposed to the accelerated corrosion environment at SNL. The difference in the appearance between these piezoelectric discs is remarkable, and the one of the left appears to be covered with a black corrosion product that has spalled off, at several locations, at the point of contact with the spring connections, probably due to repeated disassembly and reassembly of the unit. To determine the composition of this black film, this sample was placed into the X-ray diffractometer and examined in the same manner as the corrosion coupons above. This analysis, Figure 30, found peaks for silver metal and silver sulfide $\left(\mathrm{Ag}_{2} \mathrm{~S}\right)$. The silver sulfide phase was identified as the same phase found on the corrosion coupons listed in Table II (acanthite). Therefore, it is concluded that, as in the microwave connection, the growth and creep of $\mathrm{Ag}_{2} \mathrm{~S}$ into the interface between the lever-type spring connections and the silver-coated piezoelectric of the alarm sounding device is responsible for the failure of this unit to make a normal alarm sound.

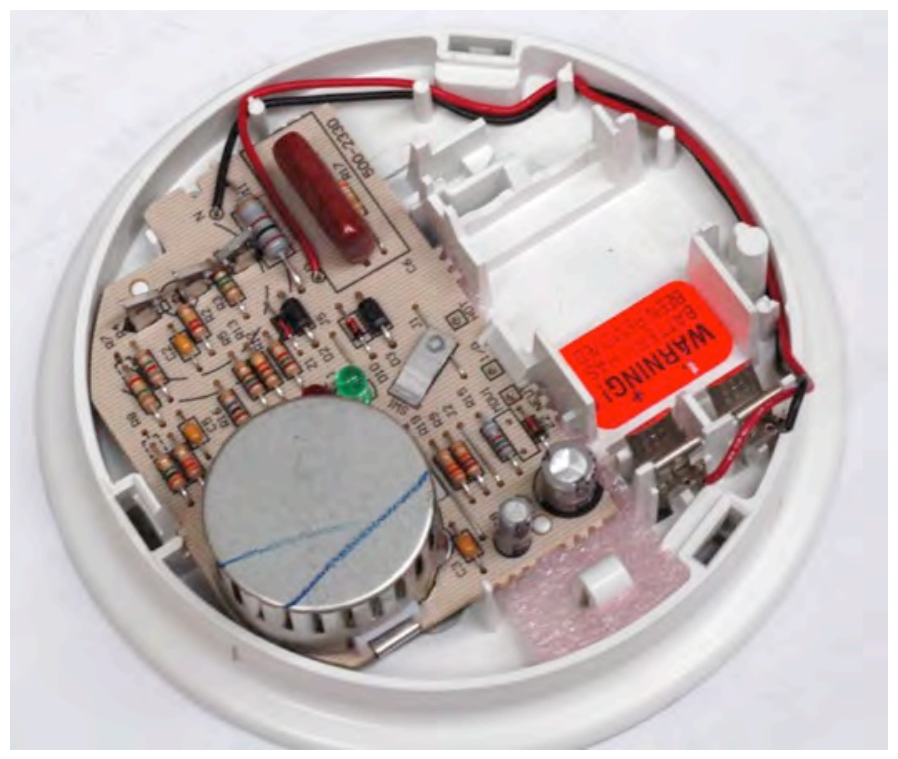

Figure 28- Open smoke detector alarm after exposure to the accelerated corrosion-testing environment at SNL. 

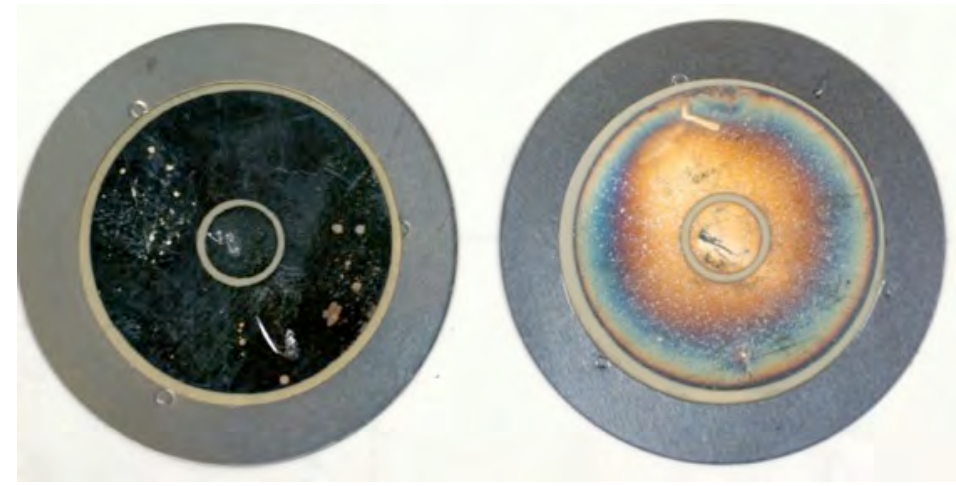

Figure 29 - Comparison of the piezoelectric alarm tone-producing disks from a smoke detector after exposure to the accelerated corrosion-testing environment at Sandia National Laboratory (on left) to one from a detector not exposed to this environment (on right). These photographs were taken after smoke response testing where the one on the left failed to produce a normal tone while the one on the right functioned normally.

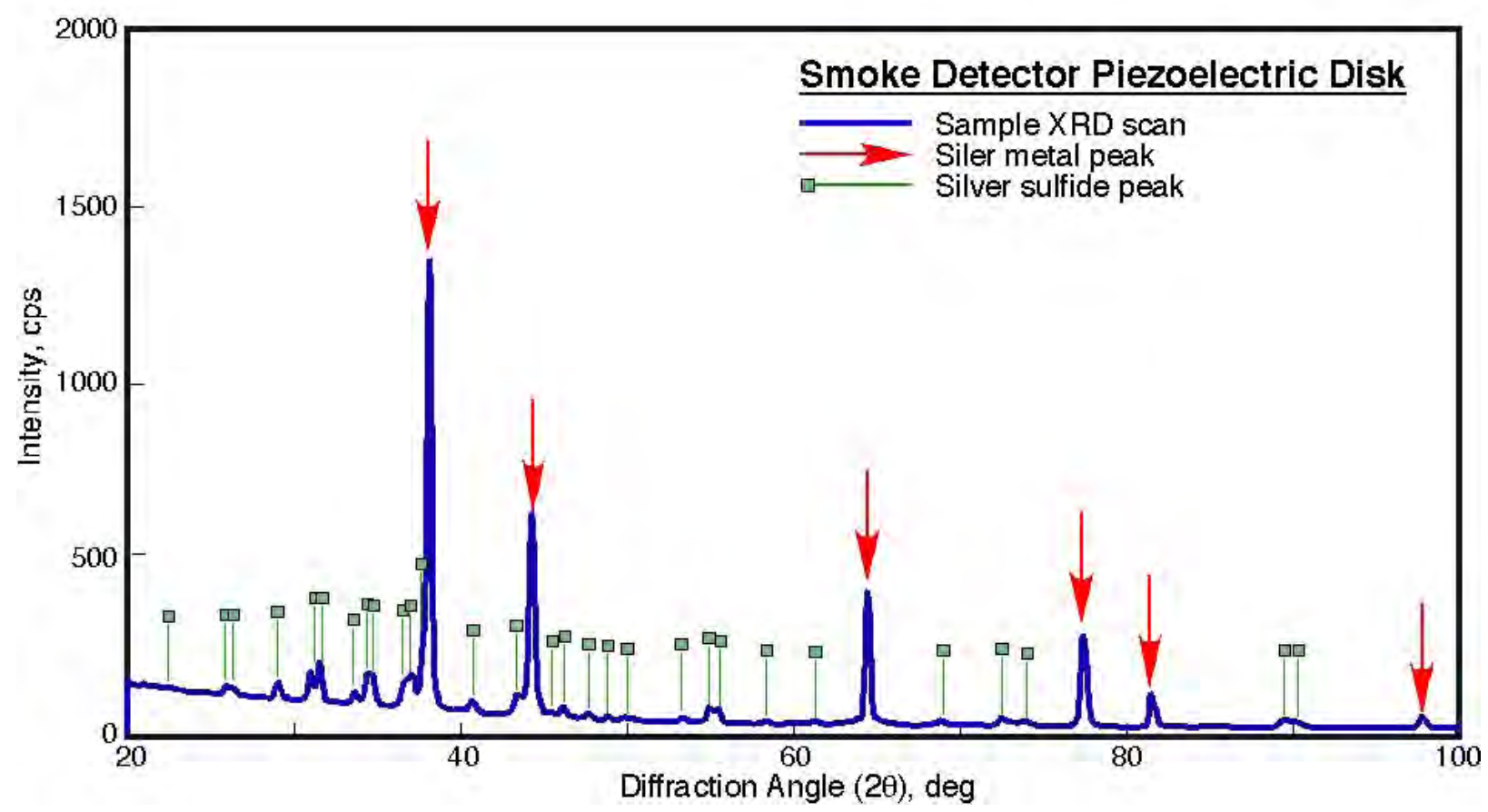

Figure 30 - X-ray powder diffraction scan showing peaks for silver and silver sulfide obtained from the surface of the piezoelectric buzzer disc shown on the left in Figure 29.

\section{Fire Sprinklers}

(1) Samples and Exposures: Fire sprinklers were exposed to the accelerated aging test environment (Table I) at the FACT II facility at SNL for 4 weeks, and this exposure should be roughly equivalent to 20 years of exposure in homes with problem drywall. The function of 
these fire sprinklers was evaluated by the NIST Fire Research Division in their sensitivity test oven (plunge test apparatus), according to the oven heat test section of Underwriter Laboratories (UL) UL 199/UL 1626. ${ }^{16}$ There are two main types of sprinkler activation elements. One type uses a glass bulb filled with a liquid that expands when heated causing the bulb to burst activating the sprinkler. The other type uses a low melting point eutectic alloy that melts when heated to activate the sprinkler. Only one of the sprinklers tested failed to operate properly after exposure to the accelerated testing environment. It was a fusible-link type sprinkler. The sprinkler that failed to operate was examined.

(2) Fire Sprinkler Results: Figure 31 shows the sprinkler that failed to activate in the NIST plunge test on the left and a sprinkler of the same design that has not been exposed to the accelerated corrosion test environment on the right. From this figure, it can be seen that exposure to the accelerated corrosion testing environment turned all of the copper and brass parts of the sprinkler a dark black color. The thin black plate slightly inclined to the viewing angle near the middle of both units is the fusible link. It is actually two plates fused together with a low melting point alloy. The copper strip in the middle is the lever that is held in place by the fusible link. When a heat source melts the fusible alloy, the two plates separate, allowing the lever to move, which releases the strut behind the lever holding the valve cap in place. Figure 32 is a close-up of the fusible links in the same units, and this figure shows how the fusible link holds the lever and the strut together, allowing the strut to keep the valve cap, shown above it, in place. The two plates fused together are similar in shape, except that opposite sides of the plates have their corners turned up in a "dog eared" fashion. As a result, this view also allows a view of the fusion zone between the two plates; however, examination of this figure indicates that a black coating of some type has been applied by the manufacturer to limit access of the external environment to the plates of the fusible link or to the low melting point alloy. Figure 33 shows two views of a fusible plate from a sprinkler that successfully activated in the plunge test at NIST. The surface that mated the plate of the opposite side and the remains of the low melting point alloy can be seen on the surface of this plate. In addition, the lip left by the fracture of the coating when the plates separated can be seen in the plane view; the oblique angle of the second photo makes it clear that this substance came over and covered the fusible alloy. Chemical analysis of this coating and the fusible alloy is beyond the scope of the present work.

Because corrosion could alter the contact of the pivot and lever mechanism, the force applied to the fusible link by the lever of the unit that failed to activate was measured by suspending weights from the lever and determining the mass that freed the fusible plate from the lever. The force the lever placed on the fusible link of the unit that failed to activate was estimated at $3.03 \mathrm{~kg} \pm 0.05 \mathrm{~kg}$ and this compares to $4.84 \mathrm{~kg} \pm 0.06 \mathrm{~kg}$ for a similar unexposed unit. While this is a large enough difference for one to detect by hand, $3 \mathrm{~kg}$ of force should still be enough force to separate the plates if the low melting point alloy between the plates melted and the plates were free to move. 




Figure 31 - A comparison between a lever-type, fusible-link fire sprinkler head after exposure to the accelerated corrosion test environment at SNL (left) and another one from the same batch that has not been exposed to this environment.

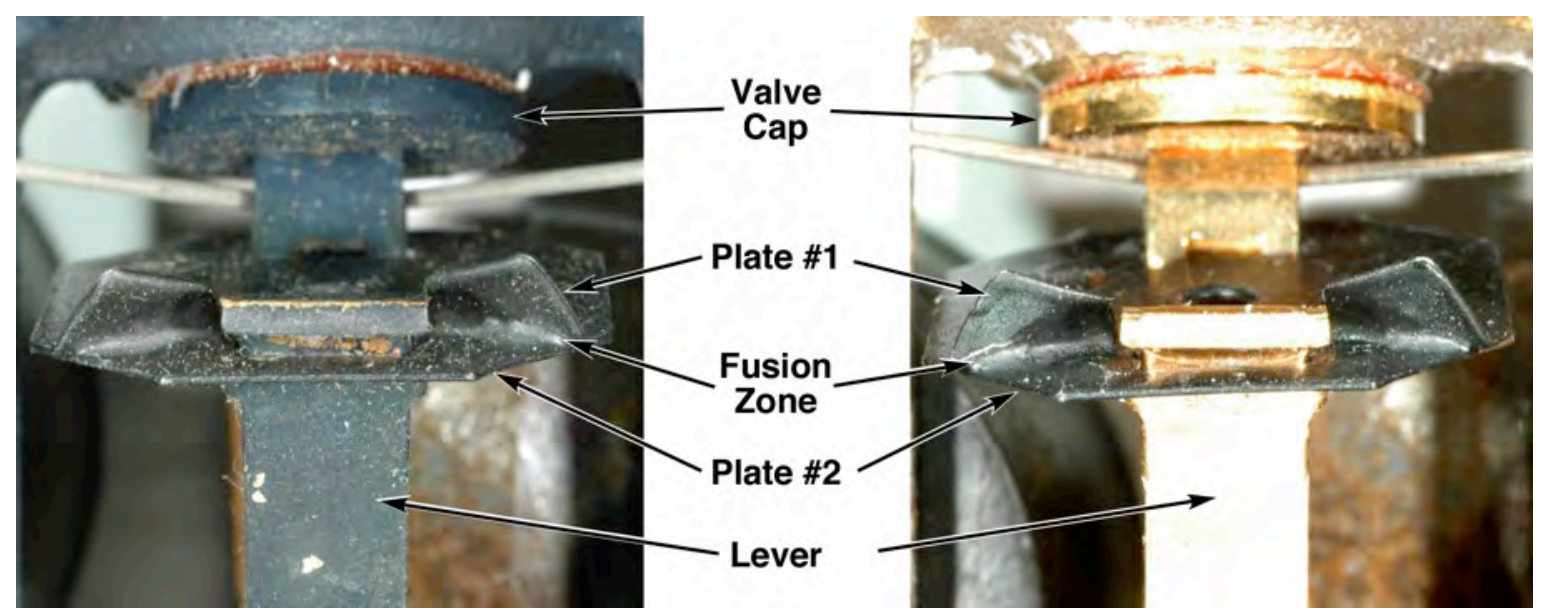

Figure 32 - Close-up of the fusible link of the units shown in Figure 31, demonstrating the gap between the two plates of the link where they are fused together. It should be noted that the black coating is on the fusible link of both the unexposed and exposed units. 

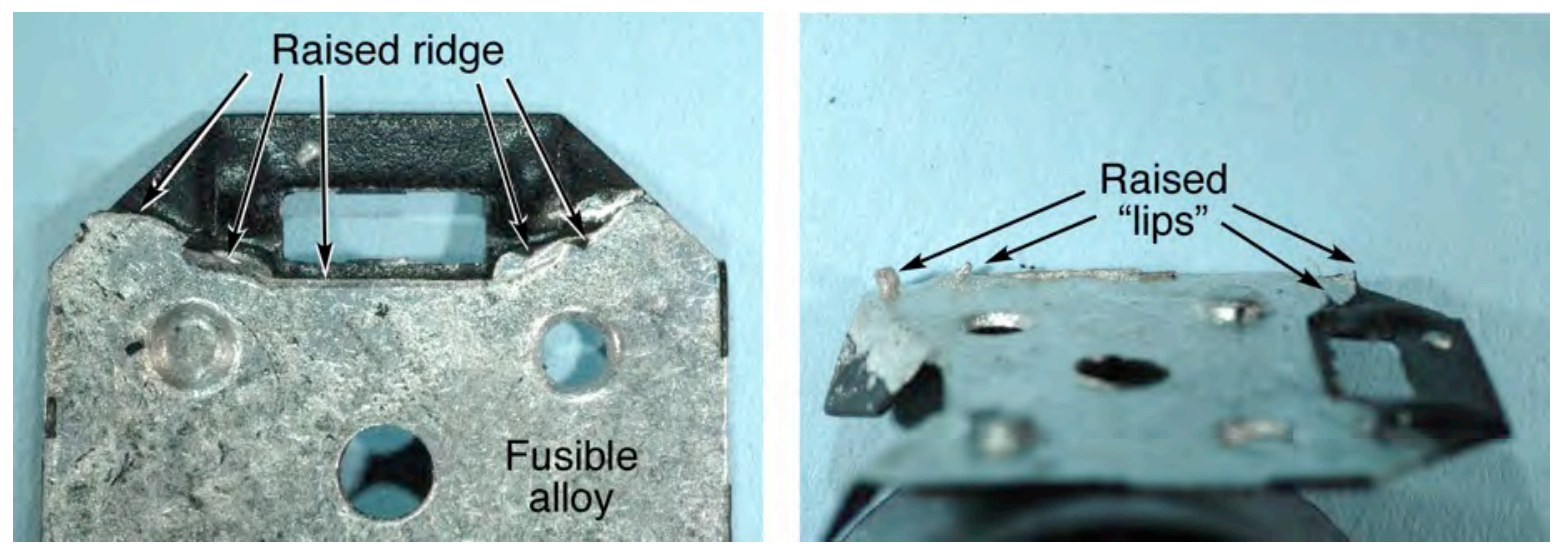

Figure 33 - Two macro photographs of the plate from a fusible link plate from a sprinkler that activated in the plunge test at NIST. The remains of the fusible alloy are the silver-colored substances in the fusion region of the plate, and the remains of the black coating can be seen to form a lip on the edge of the fusion zone.

\section{DISCUSSION}

Figure 34 is a diagram of the stable phases of oxygen and hydrogen sulfide, at different partial pressures, on the surface of copper (concentration or activities). This diagram was created from the assembled list of postulated chemical reactions in Appendix A. The free energy change was calculated using the data of Wagman et al., ${ }^{17}$ and the equilibrium line determined for the reaction with respect to variable oxygen and hydrogen sulfide partial pressures. For these calculations, it was assumed that the total gas pressure was 1 barr (approximately atmospheric pressure) and the relative humidity was assumed constant at 31.6 percent (where $\log _{10}\left[\mathrm{H}_{2} \mathrm{O}\right]=$ 0.5 ). By examining this figure, it can be seen that copper sulfide and copper oxide are stable-tovery low concentrations of these gasses in an atmosphere. The relative position of the $\mathrm{Cu}_{2} \mathrm{~S}$ and the $\mathrm{CuS}$ phase fields in this diagram indicates that increasing the hydrogen sulfide concentration (as measured by partial pressure in the diagram), causes the stoichiometry of the stable phase to shift to a lower $\mathrm{Cu} / \mathrm{S}$ ratio. Wagman et al. ${ }^{17}$ provide thermodynamic data for only two of the copper sulfide phase that can form. Fourteen different phases have been identified in the Copper-sulfide system, ${ }^{18-20}$ but the composition of these lie between these two extremes. Copper sulfides are non-stoichiometric compounds that will exchange ions with the atmosphere to equilibrate at intermediate concentrations of hydrogen sulfide. Therefore, it is not too surprising that a different phase of copper sulfide was found on the laboratory samples, as compared to that found in the homes with problem drywall. The greater concentration of hydrogen sulfide used in this environment to accelerate the test just moved the stoichiometry of the corrosion product to one of the lower $\mathrm{Cu} / \mathrm{S}$ ratio sulfides. 


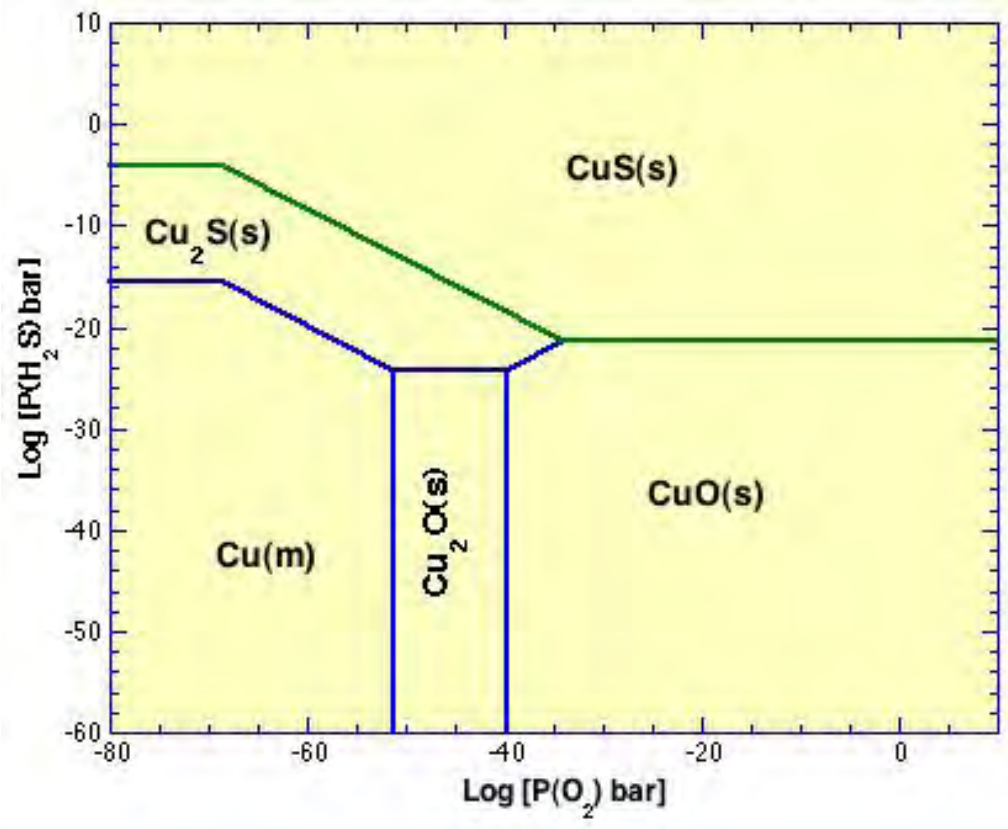

Figure 34 - Diagram of the stable phases on copper metal as a function of the oxygen and hydrogen sulfide partial pressures (concentrations). This diagram assumes that the activity of water vapor in this atmosphere is constant at 31.6 percent relative humidity.

It is interesting to note that both of the failures of electrical circuits observed in this study were at silver contacts in circuits that use relatively low voltages. Copper wire and contacts were present in the same systems, and yet the initial failure was with contacts that used silver. Copper and silver sulfides have a wide range of electrical conductivities, ${ }^{21}$ and the failure of silver contacts in industrial environments contaminated with hydrogen sulfide is a long-studied and well-recognized problem. ${ }^{22}$

While hydrogen sulfide is an unusual contaminant in residential atmospheres in the United States, it is not an uncommon component at low levels in a number of industrial environments and industrial gases. Hydrogen sulfide is a common contaminant present in fuel gasses, including natural gas. The corrosion of copper pipes for fuel gas distribution has been a concern in this industry and home construction for a number of years. Studies have been conducted to determine if it is safe to use copper tubing for fuel gasses that will be contaminated with hydrogen sulfide. ${ }^{23}$ The Copper Development Association (CDA) and the International Association of Plumbing and Mechanical Officials have published documents on the use of copper for natural gas and other fuel gasses. ${ }^{24}$

The reason why the fire sprinkler failed to function in the plunge test has not been determined, and it may be difficult to ascertain unequivocally why this unit failed to operate properly in this test. The force applied by the lever to the fusible link was measured and found to be less than that of a unit not exposed to the corrosive atmosphere at SNL; however, there was still significant force on the link to pull it apart if the low melting point alloy melted at the correct temperature. This failure to operate could be due to a manufacturing defect, some change 
in the system caused by the corrosion, or a combination of these. However, there is no obvious visual evidence that the fusible link is damaged or assembled incorrectly. It appears identical to new sprinklers and those that worked properly. The melting point of the fusible alloy could be higher than normal, due to an error in manufacturing, or due to the selective corrosion of one of the alloy constituents from the edge of the fusible link leaving behind an alloy of the unattacked constituents, but one with a higher melting point. Dealloying, as this phenomenon is known, is common in alloys composed of active and noble elements. However, close examination of the crevice - where the plates of the fusible link mate and the low melting point alloy should reside - did not disclose any evidence of corrosion products that would indicate a problem of this sort. Additional studies on this unit, including metallurgical sectioning and chemical analysis of the alloy between the plates in the fusible link, should confirm or eliminate this hypothesis.

\section{CONCLUSIONS}

All of the corrosion damage observed to date is consistent with a general attack form of atmospheric corrosion that will progress in a relatively uniform and predictable manner. No evidence of any form of localized corrosion was found on any of the samples examined, to date. This includes samples removed from homes with problem drywall and the samples exposed to the accelerated testing environment at SNL. The sulfides produced by this attack are dark, opaque substances, such that a thin film dramatically alters the appearance of susceptible metals, such as copper, silver, and alloys of these metals. However, the rate and depth of attack are relatively small compared to the safety factors typically used in design and materials selection for structural applications, where maintaining mechanical strength is critical to preventing failure. Therefore, it is concluded that this attack should not be expected to cause structural failures within the 40 years the corrosion tests were intended to represent, and this includes the copper pipes and brass fittings used to supply fuel gas to the homes.

Applications where appearance or some other surface-related property is important will be another matter. Applications that rely on reflectivity (e.g., silver mirrors), surface contact (valve seats), electrical conductivity of mechanical contacts, or sliding contact may find the growth of a dark semiconducting (or semi-insulating) layer disruptive to their normal function. Evidence of this was found in the microwave failure and the smoke alarm that was examined. Therefore, it is concluded that applications where a small quantity of critically placed corrosion can have an impact on function will be susceptible to failures by this form of attack. Atmospheric gases can permeate into systems and components that do not normally see corrosive substances and where corrosion resistance is not a large consideration in their design.

\section{ACKNOWLEDGEMENTS}

A number of people contributed to this work at different stages of this investigation. While we cannot acknowledge everyone who assisted in this investigation, those who were particularly helpful include R. Khanna of CPSC, R. Sorenson and S. Luceron of SNL, and J. Averil, E. Hnetkovsky, and A. Putorti, and of NIST Finally, the support of the U.S. Consumer Product Safety Commission is greatly appreciated. 


\section{REFERENCES}

1. N. de Zoubov, C. Vanleugenhaghe and M. Pourbaix, in Atlas of Electrochemical Equilibria in Aqueous Solutions, edited by M. Pourbaix (NACE International, Houston, TX, 1974), pp. 384-392.

2. G. Valensi, J. VanMuylder and M. Pourbaix, in Atlas of Electrochemical Equilibria in Aqueous Solutions, edited by M. Pourbaix (NACE International, Houston, TX, 1974), pp. 545-553.

3. K. Barton, Protection Against Atmospheric Corrosion - Theories and Methods. (J. Wiley \& Sons, New York, 1976).

4. D. W. Rice, R. J. Cappell, P. B. P. Phipps and P. Peterson, in Atmospheric Corrosion, edited by W. H. Ailor (J. Wiley \& Sons, New York, 1982), pp. 651-666.

5. D. W. Rice, R. J. Cappell, W. Kinsolving and J. J. Laskowski, Journal of the Electrochemical Society 127 (4), 891-901 (1980).

6. $\quad$ S. J. Glass, C. D. Mowry and N. R. Sorensen, 2009.

7. W. H. Abbott, IEEE Transactions on Components, Hybrids, and Manufacturing Technology 11 (1), 22-35 (1988).

8. W. H. Abbott, Materials Performance (6), 55-58 (1991).

9. Anon., 2010.

10. J. Guthrie, B. Battat and C. Grethlein, The AMPTIAC Quarterly 6 (3), 11-15 (2002).

11. ASTM G30-97, in Annual Book of ASTM Standards (ASTM Intl., West Conshohocken, PA, 2009), Vol. 03.01.

12. ASTM G58-85, in Annual Book of ASTM Standards (ASTM Intl., West Conshohocken, PA, 2011), Vol. 03.01.

13. ASTM G01-03, in Annual Book of ASTM Standards (ASTM Intl., West Conshohocken, PA, 2003), Vol. 03.01.

14. ASTM G46-94, in Annual Book of ASTM Standards (ASTM Intl., West Conshohocken, PA, 2005), Vol. 03.01.

15. J. D. Averill, R. G. Gann, D. C. Murphy and W. F. Guthrie, 2011.

16. A. D. Putorti, J. D. Averill, R. G. Gann and W. F. Guthrie, 2011.

17. D. D. Wagman, W. H. Evans, V. B. Parker, R. H. Shumm, I. Halow, S. M. Bailey, K. L. Churney and R. L. Nuttall, Journal of Physical and Chemical Reference Data 11 (Suppl. No. 2), 1-392 (1982).

18. M. E. Fleet, in Sulfide Mineralolgy and Geochemistry, edited by D. J. Vaughan (2006), Vol. 61, pp. 365-419.

19. E. Makovicky, Review in Mineralogy \& Geochemistry 61, 7-125 (2006).

20. N. N. Greenwood and A. Earnshaw, Chemistry of the Elements. (Pergamon Press, NY, 1984).

21. M. H. Hebb, J. Chem. Phys. 20 (1), 185-190 (1952).

22. G. Russ, IEEE Transactions on Parts, Materials, and Packaging 6 (4), 129-137 (1970).

23. F. F. Lyle, Final Rpt. Cont. No. 5088-271-1703, 1993.

24. P. Campbell, in IAPMO Official (Intl. Association of Plumbing and Mechanical Officials, 2004), pp. 12-18. 


\section{Appendix A \\ List of Reactions Between Atmospheric Air Contaminated with $\mathrm{H}_{2} \mathrm{~S}$ and the Surface of Copper Metal and Copper Bearing Alloys}

I. Reactions between copper metal $(\mathrm{Cu})$ and:

(1) oxygen to form cuprous oxide,

$$
4 \mathrm{Cu}+\mathrm{O}_{2} \leftrightarrow 2 \mathrm{Cu}_{2} \mathrm{O}
$$

and this is related through the dissociation of water to the reaction,

$$
2 \mathrm{Cu}+\mathrm{H}_{2} \mathrm{O} \leftrightarrow \mathrm{Cu}_{2} \mathrm{O}+\mathrm{H}_{2}
$$

(2) oxygen to form cupric oxide,

$$
2 \mathrm{Cu}+\mathrm{O}_{2} \leftrightarrow 2 \mathrm{CuO}
$$

and this is related through the dissociation of water to the reaction,

$$
\mathrm{Cu}+\mathrm{H}_{2} \mathrm{O} \leftrightarrow \mathrm{CuO}+\mathrm{H}_{2}
$$

(3) hydrogen sulfide to form cuprous sulfide,

$$
2 \mathrm{Cu}+\mathrm{H}_{2} \mathrm{~S} \leftrightarrow \mathrm{Cu}_{2} \mathrm{~S}+\mathrm{H}_{2}
$$

and this is related through the dissociation of water to the reaction,

$$
4 \mathrm{Cu}+2 \mathrm{H}_{2} \mathrm{~S}+\mathrm{O}_{2} \leftrightarrow 2 \mathrm{Cu}_{2} \mathrm{~S}+2 \mathrm{H}_{2} \mathrm{O}
$$

(4) hydrogen sulfide to form cupric sulfide,

$$
\mathrm{Cu}+\mathrm{H}_{2} \mathrm{~S} \leftrightarrow \mathrm{CuS}+\mathrm{H}_{2}
$$

and this is related through the dissociation of water to the reaction,

$$
2 \mathrm{Cu}+2 \mathrm{H}_{2} \mathrm{~S}+\mathrm{O}_{2} \leftrightarrow 2 \mathrm{CuS}+2 \mathrm{H}_{2} \mathrm{O}
$$

II. Reactions between cuprous oxide $(\mathrm{Cu} 2 \mathrm{O})$ and:

(5) oxygen to form cupric oxide, 


$$
2 \mathrm{Cu}_{2} \mathrm{O}+\mathrm{O}_{2} \leftrightarrow 4 \mathrm{CuO}
$$

and this is related through the dissociation of water to the reaction,

$$
\mathrm{Cu}_{2} \mathrm{O}+\mathrm{H}_{2} \mathrm{O} \leftrightarrow 2 \mathrm{CuO}+\mathrm{H}_{2}
$$

(6) hydrogen sulfide to form cuprous sulfide and water vapor,

$$
\mathrm{Cu}_{2} \mathrm{O}+\mathrm{H}_{2} \mathrm{~S} \leftrightarrow \mathrm{Cu}_{2} \mathrm{~S}+\mathrm{H}_{2} \mathrm{O}
$$

and this is related through the dissociation of water to the reaction,

$$
2 \mathrm{Cu}_{2} \mathrm{O}+2 \mathrm{H}_{2} \mathrm{~S} \leftrightarrow 2 \mathrm{Cu}_{2} \mathrm{~S}+\mathrm{O}_{2}+2 \mathrm{H}_{2}
$$

(7) hydrogen sulfide and oxygen to form cupric sulfide,

$$
2 \mathrm{Cu}_{2} \mathrm{O}+4 \mathrm{H}_{2} \mathrm{~S}+\mathrm{O}_{2} \leftrightarrow 4 \mathrm{CuS}+4 \mathrm{H}_{2} \mathrm{O}
$$

and this is related through the dissociation of water to the reaction,

$$
\mathrm{Cu}_{2} \mathrm{O}+2 \mathrm{H}_{2} \mathrm{~S} \leftrightarrow 2 \mathrm{CuS}+\mathrm{H}_{2} \mathrm{O}+\mathrm{H}_{2}
$$

III. Reactions between cupric oxide $(\mathrm{CuO})$ and:

(8) hydrogen sulfide to form cuprous sulfide,

$$
2 \mathrm{CuO}+\mathrm{H}_{2} \mathrm{~S} \leftrightarrow \mathrm{Cu}_{2} \mathrm{~S}+\mathrm{H}_{2}+\mathrm{O}_{2}
$$

and this is related through the dissociation of water to the reaction,

$$
4 \mathrm{CuO}+2 \mathrm{H}_{2} \mathrm{~S} \leftrightarrow 2 \mathrm{Cu}_{2} \mathrm{~S}+2 \mathrm{H}_{2} \mathrm{O}+\mathrm{O}_{2}
$$

(9) hydrogen sulfide to form cupric sulfide,

$$
\mathrm{CuO}+\mathrm{H}_{2} \mathrm{~S} \leftrightarrow \mathrm{CuS}+\mathrm{H}_{2} \mathrm{O}
$$

and this is related through the dissociation of water to the reaction,

$$
2 \mathrm{CuO}+2 \mathrm{H}_{2} \mathrm{~S} \leftrightarrow 2 \mathrm{CuS}+2 \mathrm{H}_{2}+\mathrm{O}_{2}
$$

(10) hydrogen sulfide to form cuprous sulfide and water, 


$$
2 \mathrm{CuO}+2 \mathrm{H}_{2} \mathrm{~S}+\mathrm{H}_{2} \leftrightarrow \mathrm{Cu}_{2} \mathrm{~S}+2 \mathrm{H}_{2} \mathrm{O}
$$

and this is related through the dissociation of water to the reaction,

$$
2 \mathrm{CuO}+2 \mathrm{H}_{2} \mathrm{~S} \leftrightarrow \mathrm{Cu}_{2} \mathrm{~S}+\mathrm{O}_{2}+2 \mathrm{H}_{2}
$$

IV. Reactions with cuprous sulfide (Cu2S) and:

(11) hydrogen sulfide to form cupric sulfide

$$
\mathrm{Cu}_{2} \mathrm{~S}+\mathrm{H}_{2} \mathrm{~S} \leftrightarrow 2 \mathrm{CuS}+\mathrm{H}_{2}
$$

and this is related through the dissociation of water to the reaction,

$$
2 \mathrm{Cu}_{2} \mathrm{~S}+2 \mathrm{H}_{2} \mathrm{~S}+\mathrm{O}_{2} \leftrightarrow 4 \mathrm{CuS}+2 \mathrm{H}_{2} \mathrm{O}
$$

